\title{
Responsabilidad ambiental por el cese de la actividad: problemas actuales y necesidad de una regulación integradora
}

\author{
José Ignacio Cubero Marcos
}

DOI: https://doi.org/10.47623/ivap-rvap.109.2017.1.03

\begin{abstract}
Sumario: I. Introducción.-II. El concepto de responsabilidad ambiental. - III. El daño y su reparación: 1. El daño ambiental y los factores que determinan su apreciación. 2. El problema de las instalaciones antiguas. - IV. La responsabilidad de los operadores: 1. Dudas en torno al carácter objetivo de la responsabilidad: incidencia de los procedimientos sancionador, penal y la responsabilidad patrimonial de la Administración. 2. La reparación y el principio costebeneficio. $-\mathrm{V}$. Los controles ex ante para el estudio previo de elementos del medio físico afectados: 1. Licencia de actividades clasificadas, comunicaciones previas y declaraciones responsables. 2. Autorizaciones ambientales integradas. 3. Declaración de impacto ambiental y ambiental estratégica ordinarias. 4. Legislación sobre residuos y suelos contaminados. -VI. Conclusiones
\end{abstract}

\section{Introducción}

En la actualidad el declive progresivo del sector industrial está generando impactos de diverso tipo más allá de los aspectos sociales o económicos como podía esperarse (1). En cinturones industriales próximos a núcleos urbanos se prevé la posibilidad de operar modificaciones en los usos, de manera que la ciudad se adapte a las nuevas demandas de sus habitantes, además de revitalizar todas esas zonas, en los planos social, económico y cultural. Ahora bien, más allá de las cuestiones urbanísticas, este estudio tiene por objeto el análisis de las repercusiones y consecuencias jurídicas que comporta el desmantelamiento o cese definitivo de ac-

(1) Acerca de los últimos indicadores sobre las rentas del negocio en las actividades extractivas y de manufactura, véase en el siguiente enlace la evolución en España de esta materia: http://www. ine.es/dyngs/INEbase/es/operacion.htm?c=Estadistica_C\&cid=1254736176958\&menu=ultiDatos\&id $\mathrm{p}=1254735576550$. 
tividades industriales, especialmente en lo que se refiere a la responsabilidad ambiental de los promotores cuyas actividades industriales generaron impactos en elementos del medio físico. Clausurada la planta, se suscitan cuestiones en torno a la obligatoriedad de restaurar el suelo, las aguas (si se producían vertidos a cauces) o las especies que pudieron resultar afectadas.

Sin perjuicio del procedimiento para iniciar la reparación, este estudio se ha centrado en algunas lagunas jurídicas o controversias que pueden suscitarse con motivo del cese de la actividad y de la apertura del procedimiento de responsabilidad medioambiental recogido en la Ley 26/2007. Se elude cualquier análisis exhaustivo de la normativa sobre responsabilidad ambiental o sobre otras consecuencias jurídicas del cese, como pueden ser las urbanísticas. En concreto, si se trata de instalaciones que han funcionado durante décadas, incluso en épocas en que los controles administrativos podían ser más laxos, se plantea el problema relativo a la determinación del daño sobre el suelo o las aguas si se desconocía el estado básico u originario en el que se encontraban cuando comenzó a funcionar la planta. Además, si no se dispone de información periódica o de informes base, como sucede en la actualidad, ¿puede realmente ser eficaz la reparación o, en su caso, los informes sobre el suelo o las aguas?

Otro problema de no menor enjundia es la más que probable responsabilidad que debe asumir la Administración cuando cesa una actividad por quiebras o insolvencia. En los tiempos actuales parece admitirse la socialización del riesgo o la pérdida, de modo que decae de un modo u otro el principio de quien contamina paga. Asimismo, los operadores que han cumplido escrupulosamente las condiciones de su autorización y logran demostrarlo, pueden verse exentos de afrontar los costes de reparación, puesto que podrían exigírselos al responsable, incluida la Administración pública. ¿Acaso el legislador, tanto interno como comunitario, han presumido que los elementos del medio físico poseen un enorme nivel de resiliencia que impide el perjuicio acumulativo? ¿Puede considerarse el daño medioambiental como continuado y depende de un examen caso por caso que permita asegurar que se ha producido el mismo y que se precisa adoptar algunas medidas? A todo ello debe añadirse la incidencia de los posibles procedimientos sancionadores o penales que pudieran iniciarse por el hecho de que se ha ocasionado un daño al medio ambiente o porque han podido no observarse los umbrales. Estos casos no pueden considerarse como responsabilidad objetiva, tal y como se ha venido insistiendo en sede doctrinal. De ese modo, la misma regulación sobre responsabilidad medioambiental se desvirtúa ante pronunciamientos jurisdiccionales que pueden determinar el nivel y el alcance de la responsabilidad. En este artículo se abordan estas y otras cuestiones, pero debe abordarse primero el concepto de responsabilidad medioambiental 


\section{El concepto de responsabilidad medioambiental}

La imputación a una persona física o jurídica de unos hechos que causan o han causado daños y perjuicios a otras es el fundamento del concepto de responsabilidad. Eso significa que, si no existe el daño o no se ha definido como tal, no puede determinarse el grado de responsabilidad(2). El daño hace referencia a un perjuicio o menoscabo que sufre en este caso un elemento del medio físico que excluye los daños personales. Todo ello requiere estudiar aquello que se ha dañado, es decir, los elementos de hecho de los que se desprende la existencia del perjuicio. La responsabilidad, a diferencia de la culpa, no exige que se haya producido una conducta ilícita o que haya ocasionado perjuicios de por sí, sino que simplemente sirve como un título de atribución de cargas a un sujeto, entidad o persona, según el cual goza de ciertas facultades que inevitablemente llevan aparejadas obligaciones que tienden a evitar o minimizar las consecuencias nocivas de su acción u omisión (3).

Así, en materia medioambiental llevar cabo actividades que comporten un riesgo para la degradación de los elementos del medio físico o para los factores ambientales, implica asumir una responsabilidad desde el momento en que, bien las normas, bien la Administración caso por caso, habilitan a sus promotores para su ejercicio (4). La responsabilidad comienza desde el mismo momento en que se deteriora el medio ambiente por la acción u omisión del ser humano(5). El desarrollo de una actividad conlleva un inicio, un desarrollo y un final. Ese proceso determina el alcance de la responsabilidad y los daños que ocasiona

(2) ZAMBONINO PULITO, M., «El sistema de responsabilidad ambiental: estudio de su régimen y límites", Revista General de Derecho Administrativo, 18, 2008. Asimismo, YANGUAS MONTERO, G., El daño no patrimonial en el Derecho del medio ambiente, Thomson Civitas, Cizur menor (Navarra), 2006, pp. 151 y 152. Asimismo, RUDA GONZÁLEZ, A., El daño ecológico puro. La responsabilidad civil por el deterioro del Medio ambiente, con especial atención a la Ley 26/2007, de 23 de octubre, de Responsabilidad Medioambiental, Thomson/Aranzadi, Cizur Menor (Navarra), 2008, in toto. GOMIS CATALÁ, L., Responsabilidad por daños al medio ambiente, Aranzadi, Pamplona, 1998 , in toto.

(3) MEILAN GIL, J.L. (Dir.), Problemas jurídico-administrativos planteados por el Prestige, Aranzadi, Cizur Menor (Navarra), 2005, pp. 190-195. El antijuridicidad en materia de responsabilidad viene vinculada al hecho de que la víctima no tiene el deber jurídico de soportar el daño.

(4) LOZANO CUTANDA, B., "La responsabilidad por daños ambientales: la situación actual y el nuevo sistema de "responsabilidad de Derecho público" que introduce la Directiva 2004/35/CE", Justicia Administrativa: Revista de Derecho Administrativo, 26, 2005, p. 6. Así, no únicamente se inicia la responsabilidad cuando sucede un perjuicio grave al medio ambiente, sino que se halla vinculada a la actividad que la origina, puesto que ésta trae el cambio adverso que implica la responsabilidad en sí.

(5) LASAGABASTER HERRARTE, I., GARCÍA URETA, A. y LAZCANO BROTÓNS, I., Derecho ambien-

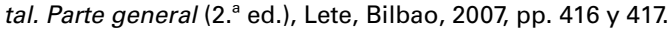


aquélla (6). Este planteamiento no es ajeno a principios básicos del Derecho ambiental, como el de corrección, puesto que siempre resulta más efectivo detectar el punto de origen en el que comenzó a sufrir perjuicios cualquier elemento del medio físico, a fin de evitar la expansión de los efectos contaminantes de las actividades humanas(7). Sin ese primer momento del proceso no puede descubrirse la evolución o cambio adverso que ha experimentado cualquier elemento $y$, en especial, si se derivan daños al mismo, tampoco puede determinarse su alcance. Además, no podría eliminarse o mitigarse el riesgo o la degradación de forma eficaz, puesto que no se implantan medidas correctoras que incidan en el foco de la contaminación, en su causa u origen (8). Por ello, lo que se ha de analizar a continuación consiste en la determinación y evaluación del daño ambiental para que la responsabilidad, que asumen entidades o personas que promueven actividades, sea real y efectiva.

\section{El daño y su reparación}

\section{El daño ambiental y los factores que determinan su apreciación}

La Directiva 2004/35 define el daño medioambiental como el ocasionado a las especies y hábitats naturales protegidos, es decir, «cualquier daño que produzca efectos adversos significativos en la posibilidad de alcanzar o de mantener el estado favorable de conservación de dichos hábitats o especies. El carácter significativo de dichos efectos se evaluará en relación con el estado básico, teniendo en cuenta los criterios expuestos en el Anexo I» (9). Los daños a las especies o hábitats naturales protegi-

(6) CASTELLANO, E., RÁBADE, J.M., et al., "Valoración y reparación de los daños al medio ambiente en España», Ecosostenible, 39, 2008. Según los autores, los métodos de valoración de riesgos han de incorporar dos hechos: que existe una recuperación naturales y que en muchas ocasiones el proyecto de recuperación requiere un tiempo para poder alcanzar el estado que tenía cuando fue dañado.

(7) MORALO IZA, V.M., «En torno a la inminente incorporación al ordenamiento jurídico español del régimen de responsabilidad ambiental comunitario", Revista de Derecho Urbanístico y Medio Ambiente, 39 (223), 2006, pp.175-176.

(8) PRIETO ÁlVAREZ, T., «Disposiciones y principios generales de la Ley 22/2011, de 28 de julio, de residuos y suelos contaminados: aproximación a su esencia y elementos estructurantes que la condicionan y conforman", GARCÍA MORENO-RODRÍGUEZ, F. (Dir.), Comentarios sistemáticos a la Ley 22/2011, de 28 de julio, de Residuos y Suelos Contaminados, Thomson Reuters/Aranzadi, Cizur Menor, 2014, pp. 102-105. Se añaden las posibles responsabilidades sancionadoras o penales, pero el hecho de generar el residuo conlleva la responsabilidad por daños.

(9) Art. 2 Directiva 2004/35/CE, de 21 de abril, que regula la responsabilidad medioambiental en relación con la prevención y reparación de daños medioambientales. Las definiciones correspondientes se recogen también en el art. 2 de la Ley 26/2007, de 23 de octubre, de Responsabilidad Medioambiental (LRM). 
dos no incluyen los efectos adversos previamente identificados, derivados de un acto del operador expresamente autorizado por las autoridades competentes o, en el caso de hábitats o especies no regulados por el Derecho comunitario, los efectos que le produzcan de conformidad con disposiciones equivalentes de la legislación nacional sobre conservación de la naturaleza(10). Sin embargo, el hecho de que una instalación se halle autorizada no conlleva la exención de responsabilidad, sino que debe examinarse si el operador ha llevado a cabo la misma conforme a las condiciones y umbrales establecidos por la legislación correspondiente(11).

El concepto de daño se extiende a las aguas, entendiéndose como tal cualquiera que produzca efectos significativos en el estado ecológico, químico o cuantitativo, o en el potencial ecológico definidos en la Directiva 2000/60/CE, de las aguas en cuestión, con excepción de los supuestos establecidos en el art. 4.7 de la Directiva 2000/60, sobre la calidad del agua, y conforme a los cuales no puede afirmarse que haya habido infracción de la misma por los estados(12). No puede ignorarse el daño causado a las aguas marinas, en la medida en que diversos aspectos del estado ecológico del medio marino no estén ya cubiertos por la Directiva 2000/60 mencionada. Por último, también son objeto de reparación los daños al suelo, es decir, cualquier contaminación del suelo que suponga un riesgo significativo de que se produzcan efectos adversos a la salud humana debido a la introducción directa o indirecta de sustancias, preparados, organismos o microorganismos en el suelo o en el subsuelo. Para la determinación de las especies y hábitats protegidos, ha de acudirse a la normativa comunitaria de referencia en esas materias, especialmente los anexos recogidos en las Directivas 79/409/CEE y 92/43/CEE (13).

(10) Véase ESTEVE PARDO, J., Ley de responsabilidad medioambiental. Comentario sistemático, Marcial Pons, Barcelona, 2008, pp. 34-38.

(11) STJUE 1 de junio de 2017, C-529/15, Gert Folk, aps. 31-33. Si la actividad ha degradado las masas de agua subterráneas incumpliendo las condiciones de la autorización, no se les puede eximir automáticamente de responsabilidad. Véase también GOMIS CATALÁ, L., Responsabilidad por..., cit., 1998, p. 139. Al tratarse, según la autora, de un sistema de responsabilidad por riesgo, parece lógico que el operador asuma el mismo y los costes que puede acarrear la reparación. El cumplimiento de las condiciones, no obstante, puede variar y el control permanente del cumplimiento podría ser innecesario.

(12) Otra excepción a tener en cuenta la contempla el art. 2.1 b) LRM, cuando se refiere a los supuestos previstos en el RD 907/2007, de 6 de julio, por el que se aprueba el Reglamento de Planificación Hidrológica.

(13) Al respecto, véase ALENZA GARCíA, J.F., «El régimen público de responsabilidad por daños ambientales en la legislación española y en la Directiva de responsabilidad ambiental», en Estudios sobre la Directiva 2004/35/CE de responsabilidad por daños ambientales y su incidencia en el ordenamiento español. Aranzadi, Cizur Menor, 2005, pp. 84-86. Distingue entre un ámbito subjetivo y otro objetivo en relación a los daños medioambientales. Estos últimos deben ser ocasionados por operadores autorizados. 
La medición o la evaluación del daño requieren un análisis previo del estado originario (o básico) del elemento del medio físico, además de la constatación de ese cambio o perjuicio hasta el momento en que se valora el mismo (14). Al respecto, se establecen unos criterios que permiten concluir si se ha ocasionado una alteración en el estado de conservación de hábitats y especies. Puede citarse al respecto el número de individuos; su densidad o la extensión de la zona de presencia; el papel de los individuos concretos; la capacidad de propagación de la especie o la capacidad del hábitat para recuperar un estado equivalente o superior al básico (resiliencia) (15). Se ha considerado, asimismo, que el carácter significativo debe valorarse en función de los umbrales y criterios establecidos en las normas concretas que afectan a cada elemento, como puede ser el caso del suelo o las especies (16).

El Real Decreto 2090/2008, de 22 de diciembre, que desarrolla la LRM, señala que «Para determinar el estado básico se analizarán los cambios que se hayan producido en el receptor como consecuencia de la acción del agente causante del daño. Podrá expresarse en términos de cambios experimentados por el receptor, con ayuda de indicadores ecológicos, como los días de uso del hábitat y la densidad de población, entre otros» (17). No se hace referencia a un estado ideal de conservación del medio, sino a aquel estado básico que presentara el medio en el momento inmediatamente anterior a la actuación del agente(18). Por otro lado, no debe olvidarse que, al objeto de exigir responsabilidad ambiental, la concurrencia de un daño es condición necesaria, pero no suficiente porque aquél ha de ser significativo(19).

La problemática principal se deriva del hecho de que la legislación tolera una serie de daños o cambios mensurables, para lo cual obliga a promotores $\mathrm{u}$ operadores a adoptar medidas correctoras o a emplear las mejores tecnologías disponibles. Eso significa que, no sólo para cuantificar el daño y la restauración a su estado originario, sino tam-

(14) La Directiva 2004/35 define el estado básico como " el estado en que, de no haberse producido el daño medioambiental, se habrían hallado los recursos naturales y servicios en el momento en que sufrieron el daño, considerado a partir de la mejor información disponible» (art. 2.1.14).

(15) Anexo I Directiva 2004/35. Véase también art. 2.2 y Anexo I LRM.

(16) LOZANO CUTANDA, B., «EI nuevo sistema de responsabilidad medioambiental para la reparación de los daños ecológicos puros», en PÉREZ ALONSO, E. et. al. (eds.), Derecho, globalización, riesgo y medio ambiente, Tirant lo Blanch, Valencia, 2012, p. 463.

(17) Art. 19.2 RD 2090/2008.

(18) LOZANO CUTANDA, B., "El nuevo sistema de responsabilidad...», cit., 2012, p. 462. Así, como ya se comentará más abajo, menciona el RD 9/2005, de 14 de enero, por el que se establece la relación de actividades potencialmente contaminantes del suelo y los criterios y estándares para determinar los suelos contaminados.

(19) LOZANO CUTANDA, B., "El nuevo sistema de responsabilidad...», cit., 2012, p. 462. 
bién para determinar si debe ser reparado conforme a la Ley, es indispensable tomar en consideración los umbrales o impactos tolerados a través de las diversas intervenciones administrativas (20). Aún así, como se comentará posteriormente, el cumplimiento de los valores límite de emisión no conlleva de por sí la ausencia del daño(21), toda vez que los impactos son acumulativos en el tiempo(22). Respecto a elementos como el suelo, procede remitirse al apartado en el que se analiza este aspecto.

\section{El problema de las instalaciones antiguas}

Otra pregunta que ha de plantearse es qué sucedería en caso de que muchas instalaciones no hubieran debido obtener autorizaciones previas o no se hubieran sometido a evaluación ambiental, por el hecho de que, en el momento en que iniciaron su actividad, la legislación no contemplaba esos mecanismos de intervención. El no sometimiento a controles previos no significa que no estuvieran obligados los promotores a colaborar con la Administración para facilitar información, inspeccionar o sancionar, imponiendo aquélla, incluso, medidas correctoras o exigiendo la implantación de mejoras tecnológicas disponibles (23).

En algunos casos a muchas instalaciones se les ha exigido la actualización de sus títulos habilitantes mediante un régimen transitorio. Podría afirmarse que los riesgos o los eventuales daños que pudieran producirse se consideraban tolerados, controlados o comprobados, por lo que podrían igualmente ajustarse estos supuestos a la exención prevista anteriormente (24).

(20) DOMIS CATALÁ, L., Responsabilidad por daños..., cit., 1998, pp. 76 y 77.

(21) YANGUAS MONTERO, G., El daño no patrimonial..., cit., 2006, pp. 130 y 131. La autora emplea el término "tolerabilidad" para referirse a esos casos en el que el daño deja de ser antijurídico.

(22) RUDA GONZÁLEZ, A., El daño ecológico..., cit., 2008, p. 115. Según el autor, "Sería poco acertado restringir el concepto de daño ecológico puro de tal modo que no pudiese comprender casos de daños causados de un modo distinto a la contaminación. [...] Se trata de un criterio restrictivo para dejar fuera del régimen normativo en cuestión ciertos tipos de daños".

(23) STJUE 1 de junio de 2017 cit. En este caso, al tratarse de una central hidroeléctrica que no se sometió a las condiciones exigidas por la Directiva 2000/60 de aguas, las autoridades competentes están obligadas a comprobar que concurren los requisitos previstos en esa Directiva antes de aprobar una autorización. De ese modo, podrían cerciorarse de que han cumplido los umbrales y demás condiciones exigibles en esa Directiva.

(24) EZEIZABARRENA SÁENZ, X., "Responsabilidad civil ambiental y energía nuclear», Revista Aranzadi de Derecho Ambiental, 20, 2011, p. 190. Uno de los problemas se plantea respecto al límite temporal para exigir la responsabilidad, pues el daño puede aparecer mucho tiempo después de haberse cerrado la instalación. 
A todo ello se añade que la LRM no se aplica a los daños medioambientales si han transcurrido más de 30 años desde que tuvo lugar la emisión, el suceso o el incidente que los causó(25). Este plazo se computa desde el día en que la emisión, el suceso o el incidente causante del daño hubieran terminado por completo(26). Este periodo de tiempo es discutible, porque no todas las zonas sufren del mismo modo los impactos de las distintas actividades, ni todas poseen la misma capacidad de recuperación.

En el Anexo I de la Directiva se establece, como momento a partir del cual puede evaluarse la existencia de responsabilidad, el momento en el que se produzca el daño, sin advertir los perjuicios, la contaminación o los efectos que hayan producido las actividades durante su funcionamiento. La actividad puede funcionar con arreglo a umbrales y valores límite adecuados pero el deterioro continuo persiste en función de su resiliencia o de las circunstancias que rodean el entorno(27). El daño puede proceder de una actividad iniciada y concluida con anterioridad a la entrada en vigor de la LRM pero puede manifestarse con posterioridad(28). No obstante, si no se ha llevado a cabo un análisis previo en origen de la situación en la que se encontraban todos aquellos elementos del medio físico, resulta muy complicado afirmar si se ha producido o no el daño y, en caso de respuesta afirmativa, qué medida de reparación es la más adecuada(29). El descubrimiento del daño en origen puede solucionar el problema relativo a las responsabilidades difusas (30). Por el contrario, la falta de datos en torno a la situación o estado básico de los elementos ambientales puede dificultar sensible-

(25) Art. 4 LRM. Al respecto, la Ley aclara que el plazo debe computarse desde el día en que haya terminado por completo o se haya producido por última vez la emisión, el suceso o el incidente que causó el daño.

(26) LASAGABASTER HERRARTE, I., GARCÍA URETA, A. y LAZCANO BROTÓNS, I., Derecho..., cit., 2007, p. 419.

(27) CASTELLANO, E., RÁBADE, J.M., eta al., "Valoración y reparación...», cit., 2008. Asimismo, MONTERO YANGUAS, G., EI daño..., cit., 2006, p. 253. Se acoge a la doctrina jurisprudencial que declara que el inicio del cómputo del plazo de prescripción de la acción se remonta al momento en que se definieron los daños, no cuando comenzaron a causarse. Todo ello atiende a la teoría de los daños continuados.

(28) VALENCIA MARTíN, G., "El impacto (favorable) de la Directiva 2004/35/CE en el "sistema" español actual de responsabilidad por daños ambientales", en Estudios sobre la Directiva 2004/35/CE de responsabilidad por daños ambientales y su incidencia en el ordenamiento español, Aranzadi, 2005, p. 150.

(29) GOMIS CATALÁ, L., Responsabilidad por daños..., cit., 1998, p. 174. Expone la virtualidad de los derechos de acceso a la información ambiental, incluso ejercitables ante particulares.

(30) VALENCIA MARTíN, G., "La responsabilidad medioambiental», Revista General de Derecho Administrativo, 25, 2010. A veces, no abrir expediente sancionador impide determinar las responsabilidades y el incumplimiento de los umbrales y valores asociados a la actividad. 
mente la determinación y alcance del daño y, en consecuencia, su reparación en origen.

La falta de sometimiento a regímenes de autorización no les exime a los promotores de cumplir los deberes de información o a implantar las medidas correctoras correspondientes (31). La misma Ley establece que, siendo los daños históricos y continuados, si se manifiestan una vez que ha entrado en vigor, podrá exigirse su reparación con arreglo a la nueva normativa. Se trata de un supuesto de retroactividad impropia que admite el ordenamiento jurídico(32). Todo ello incluye, como se analiza en este trabajo, la situación jurídica de administraciones y operadores cuando se cesa en la actividad. Los controles de tracto sucesivo comentados anteriormente deberían servir para determinar el daño que han sufrido los elementos del medio físico y, en consecuencia, exigir la correspondiente responsabilidad al promotor de la actividad(33). A todos ellos debe añadirse la cláusula de progreso técnico o adaptación a las mejores tecnologías disponibles que recogen las autorizaciones ambientales integradas (34). El problema de estos daños continuados o latentes reside en que no pueden preverse con exactitud y resultará complicado su aseguramiento (35).

\section{La responsabilidad de los operadores}

El régimen de responsabilidad objetiva para los operadores autorizados conforme al anexo III consiste en asumir las labores de prevención, evitación y reparación, siempre que medie un nexo causal entre la ac-

(31) KEMELMAJER DE CARLUCCI, A., «EI principio precautorio en la responsabilidad ambiental», Revista Crítica de Derecho Privado, 10, 2013, pp. 591-640. Los avances tecnológicos permiten reducir la contaminación, pero a veces implican más riesgos.

(32) GARCÍA AMEZ, J., "La Ley de Responsabilidad Ambiental: una visión crítica y balance de su aplicación", Revista Aranzadi de Derecho Ambiental, 30, 2015, p. 445.

(33) Al respecto, en el Anexo III de la Directiva se contemplan las actividades que pueden generar responsabilidad, entre las que se encuentran las sometidas a los controles previos para la prevención y el control integrados de la contaminación; las actividades de gestión, recogida, transporte, recuperación y eliminación de residuos; los vertidos en aguas interiores superficiales o subterráneas sujetas a autorización previa; la captación y represamiento de aguas; el tratamiento de sustancias peligrosas y biocidas; los transportes por carretera, ferrocarril, vías fluviales, marítimo o aéreo; la liberación y confinamiento de Organismos Genéticamente Modificados; la explotación de instalaciones sujetas a una autorización para el control de la contaminación atmosférica; la gestión de los residuos de extracción y la explotación de emplazamientos para el almacenamiento de dióxido de carbono.

(34) SORO MATEO, B., "Consideraciones críticas sobre el ámbito de aplicación de la Ley de responsabilidad ambiental», Revista Aragonesa de Administración Pública, 35, 2009, p. 211.

(35) RUDA GONZÁLEZ, A., El daño ecológico..., cit., 2008, p. 438. 
ción u omisión y el daño ocasionado (36). La autoridad debe disponer de indicios plausibles que puedan constituir la base de la presunción de responsabilidad $y$, con toda seguridad, de la inversión de la carga probatoria (37) o el empleo de una mayor diligencia que la que puede exigirse normalmente (38). En todo caso, han de adoptar las medidas de reparación correspondientes si se han ocasionado daños a los elementos ambientales que contempla la Ley en caso de cese de actividad (39). Ahora bien, si prueban que obraron sin culpa o negligencia pueden recuperar los costes previamente sufragados mediante la acción de repetición (40). Deben demostrar que el daño ha sido causado por una emisión o hecho permitidos por una autorización expresa, y plenamente ajustados a las condiciones en ella fijadas, concedida por, u otorgada de conformidad con las disposiciones reglamentarias y legales nacionales (41). Además, también pueden recuperar los costes si demuestran que las actividades no se habían considerado potencialmente perjudiciales para el medio ambiente según el estado de los conocimientos técnicos y científicos existentes en el momento en que tuvo lugar la emisión o la actividad (riesgos del desarrollo) (42), o que habían sido

(36) JORDANO FRAGA, J., "La responsabilidad por daños ambientales en el Derecho de la Unión Europea: análisis de la Directiva 2004/35, de 21 de abril, sobre Responsabilidad Medioambiental», Medio Ambiente \& Derecho: Revista Electrónica de Derecho Ambiental, 12 2005. Acerca de este régimen de responsabilidad objetiva, puede añadirse la opinión de otros autores, como la de DE LAS HERAS OJEDA, M., «Responsabilidad ambiental: el derecho español y comunitario. Medio Ambiente \& Derecho", Revista Electrónica de Derecho Ambiental, 17, 2008. Asimismo, BOLAÑO PIÑEIRO, M.C., "Responsabilidad en la limpieza y recuperación de los suelos declarados contaminados o alterados en la normativa de suelos contaminados", Revista de administración pública, 196, 2015, p. 336. También ha de tenerse en cuenta que en materia de contaminación de suelos prevalece la responsabilidad objetiva, sin que, incluso se analice el nexo causal.

(37) STJUE 9 de marzo de 2010, C-378/08, Raffinerie Mediterranee (ERG) SpA, aps. 57 y 58 . A este régimen general cabe añadir que la autoridad competente no se encuentra obligada a demostrar, para los operadores autorizados, comprendidos en el anexo III de la Directiva (y del anexo III LRM), que han incurrido en culpa o negligencia (ap. 62). Incluso, se afirma que la responsabilidad se les imputa a estos operadores de manera objetiva. Al respecto, véase también RUDA GONZÁLEZ, A., El daño ecológico..., cit., 2008, p. 335. El demandado puede verse obligado, incluso, a practicar una prueba diabólica de un hecho negativo. Del mismo modo, parece excesivo, admite el autor, que se requiera a alguien la prueba de una seguridad absoluta o situación de riesgo cero, en la que una actividad, sustancia o instalación es absolutamente inofensiva.

(38) YANGUAS MONTERO, G., El daño no patrimonial...., cit., 2006, p. 185.

(39) VALENCIA MARTÍN, G., "La responsabilidad medioambiental», Revista General de Derecho Administrativo, 25, 2010. Califica la responsabilidad como objetiva e ilimitada.

(40) Art. 14.2 LRM. Les corresponde a los operadores la carga probatoria diabólica de demostrar que no incurrieron en culpa o negligencia. Véase DOPAZIO FRAGUÍO, P., «Responsabilidad empresarial por riesgos ambientales en España: implicaciones jurídicas y estratégicas", Revista de Estudios Jurídicos UNESP, 20, 2010, pp. 1-24. La autora entiende que ni siquiera es necesario probar el nexo causal entre la acción y omisión del operador del anexo III y el resultado dañoso.

(41) ESTEVE PARDO, J., Ley de responsabilidad..., cit., 2008, p. 48.

(42) Art. 8.4 b) Directiva 2004/35. 
causadas por terceras personas que ejercieran una actividad, lo que sucede en el caso de los propietarios del suelo que no poseen la condición de operadores (43).

\section{Dudas en torno al carácter objetivo de la responsabilidad: incidencia de los procedimientos sancionador, penal y la responsabilidad patrimonial de la Administración}

Si bien se contempla aquí una inversión de la carga de la prueba (44) -inherente a un sistema de responsabilidad objetiva - la normativa comunitaria parece distinguir entre la responsabilidad, por un lado, y la culpa, por otro. Un operador incluido en el anexo III, en principio, debe adoptar las medidas de prevención, evitación y reparación, sin perjuicio de que repercuta los costes correspondientes, incluso a la Administración, si demuestra no haber incurrido en culpa o negligencia (45). En sede doctrinal se ha abierto un debate en torno al carácter objetivo de la responsabilidad de los operadores que han resultado absueltos en procedimientos sancionadores o penales, precisamente porque se ha acreditado el cumplimiento de umbrales o condiciones incluidas en las autorizaciones o licencias (46). En aquellos procedimientos no se admite la inversión de la carga de la prueba, con lo que, en ocasiones, ha de esperarse el faIlo del juez o tribunal competente, al objeto de que declare determinados hechos como probados (47). La normativa sobre responsabilidad ambien-

(43) STJUE 4 de marzo de 2015, C-534/13, Fipa Group, aps. 57 y 58. Se trataba de operadores que habían adquirido terrenos contaminados por actividades anteriores, en concreto, producción de pesticidas o herbicidas. La autoridad italiana les exigía adoptar una serie de medidas que impidieran la transferencia de la contaminación a la capa freática del suelo. Asimismo, véase SAN 19 de julio de 2016, RJCA 2017/272, FD 6. ${ }^{\circ}$ La existencia de una infraestructura, como tal, podría causar daños, pero su reparación siempre debe proceder de una actividad e imputarse a sus promotores.

(44) ÁLVAREZ LATA, N., "Precisando algunas reglas de la responsabilidad medioambiental: análisis del alcance de las Sentencias del Tribunal de Justicia (Gran Sala) de 9 de marzo de 2010 [TJCE 2010/70 y 2010/69]", Revista General de Derecho Europeo, 24, 2011. Se trata de una presunción del nexo causal con inversión de la carga de la prueba.

(45) Se cuestiona abiertamente el carácter objetivo de la responsabilidad, tal y como mencionó LEE, M., "New environmental liabilities LEE, M., "New environmental liabilities: the purpose and scope of the contaminated land regime and the environmental liability Directive», Environmental Law Review, 11, 2009, 2009, p. 273.

(46) SORO, B., "Consideraciones críticas...", cit., 2009, p. 211. GARCÍA AMEZ, J. "La Ley de responsabilidad...", cit., 2015, pp. 453 y 454. Asimismo, véase CONDE ANTEQUERA, J., "El deber de restauración derivado de la existencia de responsabilidad del sujeto particular causante del daño ambiental por la infracción administrativa», Revista Aragonesa de Administración Pública, 24 2004, p. 127.

(47) VALENCIA MARTíN, G., "Responsabilidad...», cit., 2010. A sensu contrario, la declaración de responsabilidad sancionadora o penal comporta someterse al régimen de responsabilidad de la LRM. 
tal en estos casos se aplica para la cuantificación del daño más que para la determinación de su alcance o las responsabilidades (48).

Se ha afirmado, incluso, que las mismas condiciones del título determinan si se ha incurrido en responsabilidad por los sujetos autorizados (49) y, en consecuencia, que solamente su inobservancia comportaría la responsabilidad medioambiental (50). En este caso, es más correcto sostener que el operador está obligado a sufragar los costes de restauración y reposición cuando su conducta sea culpable, mientras que, solamente por el riesgo que asumen, han de adoptar medidas de reparación de forma inmediata, ya que se les considera responsables. En un procedimiento posterior les corresponderá demostrar que han respetado las condiciones y umbrales fijados en los títulos, salvo que ya se hayan ventilado las responsabilidades en la vía contencioso-administrativa o penal.

Desde otra perspectiva, también podría plantearse la responsabilidad patrimonial de la Administración si los requisitos o condiciones de la regulación han resultado inadecuados(51). Otro supuesto de responsabilidad patrimonial se deriva de la actuación de la Administración tardía o negligente o la omisión administrativa (52). Lo indispensable en un sistema de responsabilidad consiste en que la reparación debe ser sufragada por un determinado patrimonio que cuente con solvencia suficiente. Así, un promotor que finaliza su actividad en quiebra o si la responsabilidad es difusa, no puede asumir los costes que se derivan de la reposición. Incluso, si afrontara los gastos derivados de la reparación, ¿a quién podría reclamar la recuperación de los costes si no han sido ocasionados por una acción u omisión de la Administración o un tercero? Los cierres de las instalaciones arrastran consigo pérdidas cuantiosas en lo económico o,

(48) Véase al respecto STS 4 de noviembre de 2011, RA 2012/1859, FD 8. ${ }^{\circ}$ Esta sentencia anula la Orden Ministerial 85/2008, de 16 de enero, por la que se establecían los criterios técnicos para la valoración de los daños al dominio público hidráulico y análisis de vertidos de aguas residuales. La sentencia distingue entre la determinación del daño, cuestión que puede regular la normativa específica sobre aguas, y su cuantificación, para lo cual es indispensable la aplicación de la normativa sobre responsabilidad medioambiental.

(49) LAWRENCE, D. y LEE, R., "Talking bout my generation: The remediation liability of waste producers", Environmental Law Review, 8, 2006, pp. 105 y 106.

(50) ALENZA GARCÍA, J.F., «El régimen jurídico...», cit., 2005, p. 89. Asimismo, ESTEVE PARDO, J., Ley de responsabilidad..., cit., 2008, p. 49. Se niega a calificar como objetiva o subjetiva la responsabilidad porque entiende que en este tipo de responsabilidad no hay víctimas o personas que puedan considerarse como tales, lo que se relativizan los modelos para calificarla o reconsiderarla.

(51) JORDANO FRAGA, J., "La responsabilidad por daños ambientales en el Derecho de la Unión europea: análisis de la Directiva 2004/35, de 21 de abril, sobre Responsabilidad medioambiental», en GARCÍA URETA, A. (coord.), Estudios de Derecho ambiental europeo, Lete, Bilbao, 2005, pp. 84 y 85.

(52) SORO, B., "Consideraciones críticas...», cit., 2009. P. 220. La autora se refiere a la culpa in vigilando. Asimismo, LOZANO CUTANDA, B., "La responsabilidad por daños...», cit., 2009, p. 17. 
simplemente, abandono de la actividad cuando las expectativas no se presentan halagüeñas (53). Se ha sostenido que, bien por riesgos del desarroIlo, bien por actuaciones de un tercero, el beneficio que reporta a la sociedad la actividad económica compensa los daños ambientales y corresponde a la Administración adoptar las medidas correspondientes (54).

\section{La reparación y el principio coste-beneficio}

Entre los criterios para llevar a cabo la reparación, se señala en la normativa la aplicación del principio de coste-beneficio, lo cual puede desvirtuar en cierta medida ese régimen de responsabilidad objetiva (55). En efecto, puede decidirse el cese de las medidas reparadoras si su coste para alcanzar el estado básico o nivel similar es desproporcionado en comparación con los beneficios medioambientales que se vayan a obtener (56). En un escenario de graves dificultades económicas para el operador, la pregunta que se suscita inmediatamente es quién ha de asumir los costes inmediatos o, en su caso, de haberlos abonado el promotor, a quién podría dirigirse para recuperarlos. Una solución, apuntada por la jurisprudencia, puede ser la venta del terreno por precio inferior al del mercado, de modo que la diferencia se emplee para la descontaminación o la adopción de diversas medidas reparadoras (57).

La Administración únicamente se halla obligada a la reparación, si la misma trata de dar cumplimiento a las exigencias de protección y preservación del dominio público o medioambientales, ya que le corresponde velar

(53) MORALO IZA, V.M., "En torno a la inminente incorporación al ordenamiento...», cit., 2006, p. 172.

(54) RUDA GONZÁLEZ, A., El daño ecológico..., cit., 2008, p. 428. Además, exigir la responsabilidad al operador en esos casos podría resultar inviable por el carácter imprevisible de los riesgos en que incurre.

(55) JORDANO FRAGA, J., "La responsabilidad...", cit., 2005. Véase también SERRANO PAREDES, O., "En torno a la existencia o no de responsabilidad ambiental por el ejercicio de actividades autorizadas", La Ley: Revista jurídica española de doctrina, jurisprudencia y bibliografía, 5, 2004, pp. 1385-1399.

(56) Anexo II, punto 1.3.3 Directiva 2004/35. La responsabilidad puede ser conjunta del operador y la Administración. La culpa in vigilando, según la autora, debe ponerse en duda, si bien depende del nivel o intensidad del control. Cuanto más intenso sea, más deberes recaen sobre la Administración para llevar a cabo el control.

(57) STS 11 de junio de 2012 (Sala de lo Civil), RA 2012/6709, FD 5. ${ }^{\circ}$ y $6 .^{\circ}$ El Tribunal entiende que, al conocer el comprador el estado en el que se encontraban los terrenos, asumía que la adquisición por precio más bajo se debía a la obligatoriedad de reposición o limpieza del suelo. Al margen de eso, se había dictado una resolución administrativa, corroborada en la vía contencioso-administrativa, que obligaba a la reparación a las entidades implicadas y directamente responsables. 
por su correcta gestión y aprovechamiento(58). Se ha interpretado que el sistema administrativo que prevé la LRM tan sólo afectaría al dominio público (59), lo que resulta cuestionable, en tanto que la transferencia de contaminación desde la propiedad privada también puede afectar al medio físico en general (60). En otras ocasiones, la recuperación de los costes deviene mucho más complicada porque recae sobre el operador la carga de culpabilizar a un tercero o ha de demostrar que el riesgo no resultaba previsible según el estado de la ciencia(61). Todo ello explica por qué se ha establecido el régimen de cauciones y garantías, si bien no siempre cubre la totalidad de los gastos (62). Por tanto, a veces la responsabilidad ambiental, más que individualizada, podría entenderse como socializada o colectiva(63), si realmente la Administración debe desempeñar las labores de reparación en última instancia ante la imposibilidad de cumplimiento por los operadores(64).

Ese régimen específico para la recuperación de los costes encuentra una laguna de cierto calado, cual es que se ignora de algún modo el efecto acumulativo de los impactos contaminantes de las activida-

(58) STS 4 de mayo de 2010, RA 3571, FD 4. ${ }^{\circ}$ Se le imputaba a la Administración responsabilidad por omisión para llevar a cabo el dragado de una zona de la Ría. Sin embargo, estas obras no eran necesarias para mantener el dominio público-marítimo en adecuado estado de conservación.

(59) CONDE ANTEQUERA, J., «El deber de restauración derivado...», cit., 2005, p. 127.

(60) SANZ RUBIALES, I., «Regulación, problemática y régimen jurídico de los suelos contaminados: especial atención tanto a su declaración, inventario y sujetos responsables, como a las diversas acciones que cabe emprender con la finalidad de recuperarlos y repararlos", en GARCÍA-MORENO RODRÍGUEZ, F. (Dir.), Comentarios sistemáticos..., cit., 2014, p. 501. Explica la tendencia a extender la responsabilidad sobre los bienes incluso de titularidad privada.

(61) CONDE ANTEQUERA, J., "Responsabilidad y restauración ambiental por riesgos del desarrollo», en PÉREZ ALONSO, E. et al., Derecho, globalización..., cit., 2012, p.501. El autor se opone a una cláusula general de exención para asumir los costes de reparación por riesgos al desarrollo y entiende que debe primar el principio de restauración. Asimismo, JORDANO FRAGA, J., «Riesgos del desarrollo como causa de exclusión en la Directiva del Parlamento y del Consejo sobre responsabilidad ambiental en relación con la prevención y reparación de daños ambientales", Revista Aranzadi de Derecho Ambiental, monográfíco, 5, 2004, p. 45. El autor se muestra contrariado porque estrechar los márgenes de responsabilidad ambiental conlleva quebrar de algún modo el principio de prevención.

(62) DE LAS HERAS, M., "Responsabilidad ambiental...», cit., 2008.

(63) VALENCIA MARTÍN, G., "El impacto...», cit., 2005, p. 153. El autor afirma que es discutible que el operador deba sufragar los costes de una actividad cuya normativa o condiciones ha cumplido estrictamente y parece legítimo exigir a la sociedad que soporte el coste de la reparación de unos daños que la sociedad consiente por considerarlos necesarios.

(64) STSJ Andalucía, de 26 de noviembre de 2010, JUR 2011/131276, FD 4. ${ }^{\circ}$ En este caso la Administración debe responder porque no ha adoptado las medidas necesarias para paliar el ruido $y$ evitar las perturbaciones que generaba en el vecindario una actividad como la de carnicería. Véase también ZAMBONINO PULITO, M. «El sistema de responsabilidad... 175, cit., 2008. Asimismo, ORTEU BERROCAL, E. y MÁROUEZ MOLERO, R., "La transposición de la Directiva 2004/35/CE, del Parlamento Europeo y del Consejo, de 21 de abril, sobre responsabilidad medioambiental en relación con la prevención y reparación de daños ambientales", Estudios sobre la Directiva 2004/35/CE de responsabilidad por daños ambientales y su incidencia en el ordenamiento español. Editorial Aranzadi, Cizur Menor, 2005, pp. 58. 
des (65). Piénsese en factorías que han funcionado durante treinta o cuarenta años sin que hayan sido sancionadas ni haya podido deducirse un leve incumplimiento de las condiciones de la autorización o los valores límite de emisión(66). Como ya lo ha planteado la doctrina, este puede ser un caso propio de responsabilidad difusa, debido a las dificultades probatorias del nexo causal (67). Los costes pueden recuperarse, a tenor de la Ley, mediante el fondo estatal de reparación de daños medioambientales cuando se generen en dominio público estatal o, en su caso, a través de los mecanismos que recojan las legislaciones autonómicas correspondientes (68). En otras palabras, la contaminación prolongada y el impacto ambiental acumulado pueden ser objeto de reparación pero mediante fórmulas de socialización del riesgo a través del dinero de los contribuyentes (69), sin perjuicio de que el elemento del medio físico que ha sufrido el daño presente una recuperación sustancial (70) o, gracias a las nuevas tecnologías, se haya controlado la contaminación o el deterioro del elemento ambiental significativamente(71).

El daño significativo tan sólo puede determinarse en tanto se conoce la situación o el estado básico del elemento ambiental agraviado. Sin esa información no puede conocerse, no ya si ha existido el daño o no, sino el origen del mismo, su evaluación y la atribución de responsabilidad (72). Sin la existencia del daño no puede haber reproche alguno y se excluye la responsabilidad, al basarse ésta en el nexo causal entre acción u omisión y perjuicio causado(73). Se necesita conocer el estado básico del ele-

(65) ALENZA GARCÍA, J.F., «El régimen público de la responsabilidad...», cit. 2005, p. 90. Por eso, puede afirmarse que la ausencia de responsabilidad sancionadora no comporta la exclusión de responsabilidad medioambiental. Así, el cumplimiento de la legalidad no excluye la antijuridicidad de la conducta (p. 95).

(66) SERAPHIM FERREIRA, G., "El nuevo régimen jurídico de la responsabilidad por daños ambientales en la Unión Europea. (La Directiva 2004/35/CE, de 21 de abril)», Noticias de la Unión Europea, 273, 2007, p. 12.

(67) GOMIS CATALÁ, L., Responsabilidad por daños..., cit., 1998, p. 89.

(68) Art. 34 LRA. Los fondos proceden de recursos procedentes de los Presupuestos Generales del Estado o, en su caso, de la financiación autonómica, articulada mediante los instrumentos de colaboración interadministrativa.

(69) La Directiva faculta a la autoridad pública para no recuperar los costes, lo que añade un problema más a la socialización del riesgo. Véase SERAPHIM FERREIRA, G., "EI nuevo régimen jurídico...", cit., 2007, p. 8.

(70) QUESADA SÁNCHEZ, A.J., "Autorización administrativa y daño en el artículo 14.2 de la ley 26/2007, de responsabilidad medioambiental: ¿paso adelante o paso atrás?", Diario La Ley, 7078. 2008.

(71) KEMELMAJER DE CARLUCCI, A., «El principio precautorio...», cit., 2010, pp. 598 y 599.

(72) LEE, M., "New environmental liabilities...», cit., 2009, p. 271. El origen del daño resulta esencial para determinar cómo distribuir la responsabilidad entre operadores.

(73) ESTEVE PARDO, J., La responsabilidad..., cit., 2008, p. 72. Resulta determinante si el operador conocía o pudo conocer que con su actividad estaba generando un daño o amenaza inminente de que se produzca y que no encontraría cobertura en el título autorizatorio. 
mento ambiental, lo que tan sólo será posible mediante los mecanismos de control ex ante a los que se sujeta el inicio de la actividad(74). Esta problemática podría evitarse si se acordaran entre operador y Administración medidas adicionales de protección cuya justificación debe probarse por éste en un periodo de tiempo (75).

\section{Los controles ex ante para el estudio previo de elementos del medio físico afectados}

La cuestión que se suscita es si los operadores autorizados o los no autorizados facilitan información suficiente acerca de los elementos del medio físico que pueden resultar afectados por sus actividades, incluidos los hábitats y la biodiversidad. Sin una información exhaustiva de esa situación o estado básico, difícilmente se reparará el daño en origen y, por tanto, las medidas a adoptar para ello pueden resultar inútiles o de escaso valor porque los bienes no van a ser recuperados en la mayor medida de lo posible o las medidas no procurarán una reparación o prevención eficaz (76). A continuación, se lleva a cabo un repaso de la normativa que contempla las técnicas de intervención y se comprobará si, en efecto, tanto la Administración como el operador disponen de la información suficiente para determinar la existencia del daño, su alcance y las medidas de reparación, una vez que ha cesado la actividad.

\section{Licencia de actividades clasificadas, comunicaciones previas y declaraciones responsables}

Para obtener la licencia de actividad se precisa la previa presentación de la solicitud a la que se adjunta un proyecto técnico. Su contenido no parece contemplar demasiadas especificaciones en torno a los elementos

(74) LAWRENCE, D. y LEE, R., "Talking bout my...», cit., 2006, p. 109. Le corresponde a la persona que ha obtenido el beneficio del elemento del medio físico la carga de la prueba de proveer información a la autoridad para la exclusión de su responsabilidad.

(75) El control más exhaustivo de la actividad permitiría disponer de información de primera mano acerca de las alteraciones que ha sufrido el elemento ambiental. Estas medidas se han implantado en algún cantón de la Confederación suiza, cuyo sistema jurídico-administrativo invita a plantear fórmulas más flexibles de relación con la Administración. Si se emplean pesticidas o se llevan a cabo vertidos, han de justificarse y demostrarse el impacto ambiental que han producido. Véase al respecto, SHEPHEARD, M. y NORER, R., "Increasing water stewardship responsibility: water protection obligations and the watershed management policy affecting farmers in Lucerne, Switzerland", Environmental Law Review, 15, 2013, pp. 126 y 127.

(76) QUESADA SÁNCHEZ, A.J., "Autorización administrativa...», cit., 2008. 
que pueden sufrir el impacto ambiental(77). El efecto de las actividades clasificadas en el medio ambiente reviste menor gravedad o riesgo que el de aquellas que requieren autorizaciones o declaraciones de impacto, por lo que la falta de exhaustividad y precisión acerca de las informaciones puede estar justificada (78). Ahora bien, como se ha comentado anteriormente, no puede desdeñarse el perjuicio acumulativo de los factores ambientales, como emisiones, residuos o vertidos.

En el Reglamento de Actividades Molestas, Insalubres, Nocivas y Peligrosas (RAMINP) se le exige al promotor la presentación de una instancia a la que ha de adjuntarse el proyecto técnico y la memoria descriptiva en que se detallan las características de la actividad, su posible repercusión sobre la sanidad ambiental y los sistemas correctores que se propongan utilizar, con expresión de su grado de eficacia y de seguridad (79). En las leyes autonómicas que han precisado o, incluso, desplazado en muchos de los aspectos al RAMINP, tampoco se contemplan más precisiones en torno al estado básico o primigenio de los posibles elementos del medio físico afectados. No se hace referencia al contenido del proyecto técnico y si debe albergar alguna información adicional, al margen de los factores que inciden en el medio ambiente, como residuos, emisiones, ruidos o vertidos y las medidas correctoras para reducir su impacto(80). A todo ello pueden exigirse informes urbanísticos o estudios acústicos (81).

En la legislación aragonesa, por ejemplo, deben preverse en ese proyecto técnico las formas de restauración del medio afectado y el programa de seguimiento de la actividad afectada, en los casos de desman-

(77) DOMPER FERRANDO, J., El medio ambiente y la intervención administrativa en las actividades clasificadas, vol. II, Civitas, Madrid, 1992, pp. 125-128. Las actividades molestas, insalubres, nocivas y peligrosas reciben una distinta aplicación práctica, pero, mediante ellas se hace referencia no exclusivamente a cuestiones relacionadas con el medio ambiente, sino también con la salud o el bienestar de las personas, como el ruido o la sanidad. Todos estos aspectos también deberían ser analizados y no siempre una evaluación ambiental del proyecto puede ponderar sus efectos reales en la población.

(78) LASAGABASTER HERRARTE, I., GARCÍA URETA, A. y LAZCANO BROTÓNS, I., Derecho ambiental..., cit., 2007, pp. 167 y 168.

(79) Art. 29 Decreto 2414/1961, de 30 de noviembre, por el que se aprueba el Reglamento de Actividades Molestas, Insalubres, Nocivas y Peligrosas.

(80) Art. 54 Ley Foral 4/2005, de 22 de marzo, de Intervención para la Protección Ambiental de Navarra. Asimismo, Art. 27.2 Decreto Legislativo 1/2015, de 12 de noviembre, por el que se aprueba el Texto Refundido de la Ley de Prevención Ambiental de Castilla y León. En esta norma se destaca fundamentalmente la obligación de incorporar medidas correctoras que se refieran a los factores que inciden en los elementos ambientales.

(81) Art. 53.2 Ley 6/2014, de 25 de julio, de Prevención de Contaminación y Calidad Ambiental de la Comunidad Valenciana. Acerca de todo ello, MERINO MOLINS, V., "Los instrumentos de intervención ambiental en la Ley 6/2014, de 25 de julio, de Prevención, Calidad y Control Ambiental de Actividades de la Comunidad Valenciana (II). La licencia ambiental y otros medios de intervención", El Consultor de los Ayuntamientos y de los Juzgados, 7, 2015, pp. 835 y 836. 
telamiento de las instalaciones y cese de la actividad(82). El seguimiento de la actividad también se incluye en los proyectos técnicos para la calificación ambiental en Andalucía, pero, incluso en vía reglamentaria no se impone la obligación de detallar el estado de los elementos afectados(83). En Cataluña la solicitud ha de adjuntar un informe que describa las características del suelo en el que se emplaza la actividad proyectada, siempre y cuando la normativa específica de aplicación defina esa actividad como potencialmente contaminante para el suelo(84). Al superponerse los títulos de intervención, en el proyecto técnico han de figurar aspectos que también deben formar parte del estudio de impacto ambiental, si bien tampoco se detallan las cuestiones que debe reflejar sobre el estado básico de los elementos del medio físico.

En algunos casos los procedimientos para obtener la licencia de actividad sufren variaciones por el hecho de que han de someterse a evaluación de impacto ambiental, lo que obliga al promotor a redactar el estudio de impacto ambiental y a incluir mayor información en el mismo en torno a los elementos del medio físico que pudieran resultar afectados e, incluso, sobre la existencia de un plan de seguimiento respecto a los impactos (85). En el caso de la legislación vasca o valenciana, únicamente debe aportarse el estudio de impacto ambiental(86), si bien habría sido más lógico unificar el procedimiento o bien esperar al pronunciamiento previo o la DIA(87). En la Ley vasca de Medio ambiente se señala la necesidad de incluir en el proyecto la descripción del medio sobre el que se

(82) Art. 76.2 b) Ley 11/2014, de 4 de diciembre, de Prevención y Protección Ambiental de Aragón.

(83) Art. 9.1 f) Decreto 297/1995, de 19 de diciembre, por el que se aprueba el Reglamento de Calificación Ambiental de Andalucía. Piénsese que este contenido también forma parte del informe previo. Redactado por técnico competente, que debe adjuntarse a la declaración previa o declaración responsable. Así, véase art. 44.5 Ley 7/2007, de 9 de julio, de Gestión de la Calidad Ambiental de Andalucía. Véase al respecto, CANO MURCIA, A., "Calificación ambiental y la declaración responsable en la Ley $7 / 2007$, de gestión integrada de la calidad ambiental de Andalucía. Análisis crítico al Decreto-Ley 3/2015", Consultor de los ayuntamientos y de los juzgados: Revista técnica especializada en administración local y justicia municipal, 9, 2015, pp. 1137-1142.

(84) Art. 39.1 b) Ley 20/2009, de 4 de diciembre, de Prevención y Control Ambiental de Actividades en Cataluña.

(85) Arts. 33 y 34 Ley 20/2009, de Cataluña. En esta normativa tampoco se recoge nada especial en torno a las características de los elementos ambientales afectados. Véase también arts. 52 y 53 Ley Foral 4/2005 de Navarra. De hecho, se contempla únicamente la descripción del proyecto y su afección al suelo y otros recursos naturales.

(86) Art. 53.2 b) Ley 6/2014, de la Comunidad Valenciana. Art. 57.1 Ley 3/1998, de 27 de febrero, de Medio Ambiente del País Vasco.

(87) MERINO MOLINS, V., "Los instrumentos de intervención ambiental en la Ley 6/2014, de 25 de julio, de Prevención, Calidad y Control Ambiental de Actividades de la Comunidad Valenciana (I). La autorización ambiental integrada", El Consultor de los Ayuntamientos y de los Juzgados, 3, 2015, pp. 323-325. 
emplace (88). En otros casos la licencia de actividad se integra en el procedimiento de autorización ambiental. Aun así, no se aprecian diferencias en cuanto al contenido del proyecto técnico (89).

Por lo que se refiere a las comunicaciones previas o a las declaraciones responsables, la legislación no prevé demasiadas precisiones en torno al estado de los elementos del medio físico, si bien puede recogerse, con las limitaciones que ello conlleva, en las memorias o proyectos técnicos que deben ser validados por técnico competente o, en su caso, si así lo exige la legislación sectorial correspondiente, por las entidades de certificación(90). En la Comunidad Autónoma vasca se requiere una "memoria en la que se incorpore la descripción de la actividad y de las medidas implantadas para minimizar el posible impacto de la actividad en el medio ambiente, las personas o sus bienes", sin más detalles en torno al estado del suelo o el resto de elementos ambientales (91). La certificación consiste en verificar que se han adoptado las medidas apropiadas para reducir los impactos posibles, sin que se haga referencia a los elementos del medio físico. Del mismo modo, el objeto de la comunicación estriba en constatar y describir el estado de las instalaciones y sus efectos medioambientales (92). En la Región de Murcia se les habilita a los ayuntamientos para establecer qué tipo de documentación deben presentar las personas que presentan una comunicación previa (93).

\section{Autorizaciones ambientales integradas}

El Real Decreto legislativo 1/2016, de 16 de diciembre, aprobó el Texto Refundido de la Ley de Prevención y Control Integrados de la Contaminación (LPCIC). Algunas actividades, recogidas en el anexo 1 del RDL, precisan para comenzar su funcionamiento la autorización ambiental integrada en los términos que establece esa misma norma y también el órgano ambiental puede decidir respecto a los valores límite de emisión o las mejo-

(88) Art. 57.1 Ley 3/1998, vasca de Medio Ambiente.

(89) Art. 76.2 Ley 4/2009, de 14 de mayo, de Protección Ambiental Integrada de la Región de Murcia.

(90) Art. 52.3 y 4 Ley 20/2009, de 4 de diciembre, de Prevención y Control Ambiental de Actividades de Cataluña. Véase también art. 68.4 Ley 6/2014, de 25 de julio, de Prevención de Contaminación y Calidad Ambiental de Comunidad Valenciana.

Ley $6 / 2014$, de 25 julio

(91) Art. 62 bis.3 Ley 3/1998, de 27 de febrero de Medio Ambiente del País Vasco.

(92) Art. 43.3 Decreto Legislativo 1/2015, de 12 noviembre, por el que se aprueba el Texto Refundido de Ley de Prevención Ambiental de Castilla y León.

(93) Art. 63.4 Ley 4/2009, de 14 de mayo, de Protección Ambiental Integrada de Región Murcia. 
ras tecnológicas disponibles (94). Esta norma parece responder a las necesidades que demanda la responsabilidad ambiental en caso de cese de la actividad(95), si bien, como se comentará posteriormente, también presenta algunas sombras. El titular de la actividad debe evaluar el estado del suelo y la contaminación de las aguas subterráneas por las sustancias peligrosas relevantes utilizadas, producidas o emitidas por la instalación de que se trate, y se le obliga a comunicar al órgano competente los resultados de dicha evaluación(96). Han de distinguirse dos situaciones: cuando al promotor se le exija informe base del estado del suelo y elementos del medio físico; y cuando no se halla obligado a presentar dicho informe con anterioridad al inicio de la actividad (97).

Así, si de la evaluación se desprende que se ha causado una contaminación significativa del suelo o las aguas subterráneas con respecto al estado establecido en el informe base, el titular de la actividad debe adoptar las medidas adecuadas para hacer frente a dicha contaminación, a fin de restablecer el emplazamiento de la instalación a las condiciones en que se encontraba en el momento inicial, antes de comenzar la actividad. Estas medidas han de respetar el anexo II de la Ley 26/2007, sobre Responsabilidad Ambiental. Además, debe repararse en la viabilidad técnica de las medidas (98).

La LPCIC también ha recogido la necesidad de conocer la situación de los elementos ambientales desde el inicio de la actividad. Así, en el proyecto que se adjunta a la solicitud, el promotor ha de informar acerca del estado ambiental del lugar en el que se ubicará la instalación y los posibles impactos que se prevean, incluidos aquellos que puedan originarse al cesar la explotación de la misma. Cuando la actividad implique el uso, producción o emisión de sustancias peligrosas relevantes, teniendo en cuenta la posibilidad de contaminación del suelo y la contaminación de las aguas subterráneas en el emplazamiento de la instalación, se reque-

(94) Acerca de la autorización ambiental integrada, véase PIGRAU SOLÉ, A., CAMPINS ERITJA, M. y BORRÁS PENTINANT, S., "La adopción de una perspectiva integrada en la política comunitaria ambiental: la Directiva $96 / 61 /$ CE relativa a la prevención y al control integrados de la contaminación", BAUCELLS I LLADÓS, J. y VERNET I LLOBET, J. (coord.), La prevención y el control integrados de la contaminación, Marcial Pons, Barcelona, 2004, p. 39.

(95) LOZANO CUTANDA, B., «El nuevo texto refundido de la ley de prevención y control integrados de la contaminación: mejora normativa y algún retoque», Diario La Ley, 8947, 2017. La prevalencia de las autorizaciones ambientales sobre las licencias de actividades clasificadas no comporta de inmediato que éstas no deban ser solicitadas y obtenidas.

(96) Art. 23.2 LPCIC.

(97) LOZANO CUTANDA, B., SÁNCHEZ LAMELAS, A. y PERNAS GARCÍA, J.J., Evaluaciones de impacto ambiental y autorización ambiental integrada. Doctrina, textos legales y jurisprudencia, La ley, Madrid, 2012, p. 639. Cuando se produzca el cese de la actividad, este estudio permitirá evaluar si la instalación ha causado una contaminación significativa del suelo o las aguas subterráneas.

(98) Art. 23.2 LPCIC. 
rirá un informe base antes de comenzar la explotación de la instalación o antes de la actualización de la autorización. Este informe contendrá la información necesaria para determinar el estado del suelo y las aguas subterráneas, a fin de hacer la comparación cuantitativa con el estado tras el cese definitivo de las actividades (99).

El documento que compone el informe ha de contener información sobre el uso actual y, si estuviera disponible, sobre los usos anteriores del emplazamiento. Si estuviesen disponibles, el promotor debe incluir los análisis de riesgos y los informes existentes regulados en la legislación sobre suelos contaminados en relación con las medidas realizadas en el suelo y las aguas subterráneas que reflejen el estado en el momento de la redacción del informe(100). Como alternativa, el informe debe incluir nuevas medidas adoptadas en el suelo y las aguas subterráneas que guarden relación con la posibilidad de una contaminación por aquellas sustancias peligrosas que vayan a ser utilizadas, producidas o emitidas por la instalación de que se trate(101). Asimismo, puede incluirse la información elaborada con arreglo a la legislación estatal, autonómica o de la Unión Europea, siempre que se ajuste a los requisitos establecidos anteriormente, es decir, desarrolle aquellos aspectos mencionados.

Habría que remontarse al Real Decreto 9/2005, de 14 de enero, para conocer alguna referencia en torno a qué sustancias o productos pueden considerarse contaminantes del suelo. Incluso, esto puede que no aporte una orientación acertada a tenor de la Ley, ya que ésta menciona el genérico término "sustancias peligrosas», para que los promotores se hallen obligados a presentar un informe preliminar de situación que debe recoger las características técnicas de la actividad y del suelo en que se ubican (102). Piénsese que un remedo del art. $23 \mathrm{LPCIC}$, que regula el cese de la actividad, había sido incorporado a la Ley 16/2002 (art. 22 bis) por la Ley $5 / 2013$, de 11 de junio, que modifica la anterior, y que tenía por objeto la transposición de la Directiva 2008/1, del Parlamento Europeo y del Consejo que, a su vez, había derogado la Directiva 96/61.

En cuanto a las sustancias peligrosas, en la actualidad, tras la modificación del Real Decreto 363/1995, de 10 de marzo, por el que se aprueba

(99) Art. 12.1 a) $3 .^{\circ}$ y f) LPCIC.

(100) DOPAZIO FRAGUÍO, P., "Responsabilidad empresarial...», cit., 2010, p. 126.

(101) LANEGRA QUISPE, I.K., "El daño ambiental en la Ley General del Ambiente. Derecho PUCP», Revista de la Facultad de Derecho, 70, 2013, pp. 191.

(102) Al respecto, véase art. 3 y anexo II RD 9/2005, de 14 de enero, por el que se establece la relación de actividades potencialmente contaminantes del suelo y los criterios y estándares para la declaración de suelos contaminados. Asimismo, aunque algo alejado de la temática, nótese que elTC, en sentencias 104 y 111/2013 ha considerado que el Gobierno dispone de competencias para establecer el contenido del informe preliminar, al encuadrarse en el ámbito de la legislación básica (FJ 8. ${ }^{\circ}$. 
el Reglamento sobre clasificación, envasado y etiquetado de sustancias peligrosas, debe hacerse la correspondiente remisión al anexo IV del Reglamento comunitario 1272/2008, del Parlamento Europeo y del Consejo, de 16 de diciembre de 2008, sobre clasificación, etiquetado y envasado de sustancias y mezclas(103). Esta disparidad de conceptos, por un lado, los productos contaminantes y, por otro, las sustancias peligrosas, impide dotarle de coherencia al régimen de responsabilidad ambiental, debido a que no sólo los operadores que emplean sustancias peligrosas ocasionan daños al medio ambiente. A todo ello la Ley introduce un elemento más de confusión: el hecho de ser "relevantes" (104). En cualquier caso, el RD 363/1995 califica como peligrosas para el medio ambiente "las sustancias y preparados que presenten o puedan presentar un peligro inmediato o futuro para uno o más componentes del medio ambiente» (105).

Respecto a los promotores que no precisan informe base, se les conmina a adoptar las medidas necesarias destinadas a retirar, controlar, contener o reducir las sustancias peligrosas relevantes para que, teniendo en cuenta su uso actual o futuro aprobado, el emplazamiento ya no cree un riesgo significativo para la salud humana ni para el medio ambiente(106). El enunciado del artículo en sí mismo causa perplejidad por su redacción o su significado en un primer momento. Por una parte, sólo se les requiere la presentación del informe base a los promotores que usen o produzcan sustancias peligrosas, mientras que aquellos que no estén obligados a elaborar y entregar dicho informe han de adoptar medidas destinadas a retirar, controlar, contener o reducir las sustancias relevantes peligrosas ¿Pueden detectarse sustancias peligrosas si un promotor ha declarado que no las usa y produce? Tal vez, implícitamente la norma se refiere a los daños acumulativos o históricos, en tanto que han podido ser causados por instalaciones anteriores.

El funcionamiento continuado de las instalaciones siempre genera un impacto y un deterioro en los elementos del medio físico que precisa en cualquier caso el restablecimiento, más allá de que se trate o no de sustancias peligrosas. Probablemente, dada la extensión de la lista de

(103) La modificación fue operada por el Real Decreto 717/2010, de 28 de mayo.

(104) PERNAS GARCÍA, J.J., "Integración y coordinación procedimental de la evaluación de impacto ambiental y de la autorización ambiental integrada", en NOGUEIRA LÓPEZ, A. (dir.), Evaluación de impacto ambiental. Evolución normativo-jurisprudencial, cuestiones procedimentales y aplicación sectorial, Atelier, Barcelona, 2009, p. 96.

(105) Art. 2.2 RD 363/1995. Se añade un listado de sustancias que pueden considerarse peligrosas, que incluyen los explosivos, las cancerígenas, las inflamables, las tóxicas, las nocivas, corrosivas o irritantes.

(106) Art. 23.4 LPCIC. 
sustancias, entre las que se encuentran las irritantes o corrosivas, parece que muchos más titulares u operadores deberían haber sido obligados a elaborar el informe base (107). Todas estas cargas vienen sensiblemente condicionadas por la tardía entrada en vigor y aplicación de las normas sobre suelos contaminados o, en su caso, la Ley sobre responsabilidad ambiental. Así, una instalación que hubiera funcionado durante veinte años es probable que no disponga de muchos de esos informes, aun habiendo empleado sustancias peligrosas. La LPCIC impone la obligación a los operadores de presentar anualmente información acerca de los valores límite de emisión, además de cumplir los requisitos que obligan a adoptar medidas y a llevar a cabo el control de sustancias peligrosas(108). La Ley no menciona el estado del elemento físico en sí, sino la presencia de sustancias peligrosas o la evolución de los valores límite de emisión.

Por lo que respecta a las legislaciones autonómicas, en Cataluña se ha pretendido implantar una especie de procedimiento administrativo de evaluación que permite al órgano competente de la Administración verificar si se han adoptado medidas de restablecimiento suficientes para permitir el cierre, de modo que el operador que cesa en la actividad se halla condicionado a la comprobación favorable(109). A partir de ese momento debe considerarse que se extinguen las cargas y deberes que pudieran recaer sobre el operador(110). En Andalucía el procedimiento es algo más complejo para el cierre definitivo de la instalación. Además de presentar un proyecto, el órgano ambiental competente debe solicitar un informe al ayuntamiento donde se ubique la instalación y a los órganos y entidades que hubiesen emitido informe vinculante en el procedimiento de concesión de la autorización ambiental integrada. Además de todos ellos, se solicitará dictamen a los órganos competentes en materia de abandono y clausura de depósitos de efluentes líquidos o de lodos procedentes de ac-

(107) LEE, M., "New environmental liabilities...», cit., 2009, p. 270. La autora se cuestiona si el incumplimiento de los estándares y el daño ambiental consiguiente debe basarse exclusivamente en la utilización o no de sustancias peligrosas, no en otros factores, como la contaminación acumulada.

(108) Art. 22.1 i) y j) LPCIC.

(109) Art. 66.4 Ley 20/2009. El Decreto Legislativo 1/2015, de 12 noviembre, de Castilla y León, por el que se aprueba el Texto Refundido de la Ley de Prevención Ambiental, se remite en su art. 48.1 a la legislación estatal básica, es decir, el Texto Refundido comentado anteriormente. Esta verificación aparece más clara en el art. 68.2 Ley 11/2014, de 4 de diciembre, del Parlamento de Aragón, sobre Prevención y protección ambiental.

(110) CASADO CASADO, L., "Novedades en el régimen de prevención y control ambiental de actividades en Cataluña: retroceso en la protección del medio ambiente versus promoción de la actividad económica", Revista Catalana de Dret Ambiental, 1, 2012, véase en http://www.cedat.cat/ca/ contacta. 
tividades, mineras, industriales y agrarias, así como otros que considere necesarios (111).

En Cataluña se les obliga a los promotores que presenten solicitud de autorización ambiental a indicar en el proyecto las características del suelo en el que se emplaza la actividad proyectada, siempre y cuando esta actividad esté definida como potencialmente contaminante del suelo por la normativa específica de aplicación(112). Como se aprecia, se emplea el término potencialmente contaminante no sólo por el uso de sustancias peligrosas, más allá de que, como se analizará posteriormente, se requiera un informe de situación o de calidad del suelo(113). En otros casos, la Ley autonómica requiere directamente la presentación del informe base cuando se prevea la posibilidad de contaminación del suelo o aguas subterráneas, si la actividad puede suponer la producción, uso o emisión de sustancias contaminantes (114). En otras comunidades no se hace referencia expresa a la documentación o contenido de la solicitud que analice el estado del suelo o las aguas(115).

\section{Declaración de impacto ambiental y ambiental estratégica ordinarias}

El órgano ambiental examina los impactos ambientales que ocasionan los proyectos o los planes que afectan a un ámbito territorial más extenso o por su carácter sectorial, así como plantea unas alternativas o solucio-

(111) Art. 41.2 Decreto, de 17 de enero de 2012, de la Junta de Andalucía, que regula autorización ambiental integrada y modifica el Decreto 356/2010, de 3 de agosto de 2010, que regula la autorización ambiental unificada. Se exige una verificación posterior aprobada por una entidad colaboradora en materia de calidad ambiental y el órgano competente podrá comprobar in situ la ejecución de medidas.

(112) Art. 17.1 e) Ley 20/2009, de 4 de diciembre, de Ley Prevención y Control Ambiental de Actividades de Cataluña. En la Región de Murcia se obliga a los promotores a incluir los informes preliminares mencionados en el Real Decreto 9/2005, de 14 de enero, por el que se establece la relación de actividades potencialmente contaminantes del suelo y los criterios y estándares para la declaración de suelos contaminados. Aquí se aprecia la diferencia de criterio antes aludida respecto a qué personas deben elaborar los informes base. Se había concluido que les correspondía a los operadores que usen, produzcan o emitan sustancias peligrosas, mientras que en este caso se refiere a "sustancias potencialmente contaminantes». Habrá ocasión más adelante para precisar qué establece al respecto la legislación sobre suelos contaminados.

(113) Este requisito del informe previo es habitual en la legislación de muchas comunidades autónomas, como Andalucía a presentar el informe de situación a los operadores obligados a ello por la Ley 7/2007, de 9 de julio, de Gestión de la Calidad Ambiental. Véase Decreto 356/2010, de 3 de agosto, de la Junta de Andalucía (art. 14.1).

(114) Art. 36.2 Ley 6/2014, de 25 julio, de Prevención de Contaminación y Calidad Ambiental de Comunidad Valenciana.

(115) Ley 11/2014, de 4 de diciembre, de Prevención y Protección Ambiental de Aragón; la Ley 17/2006, de 11 de diciembre, de Control Ambiental Integrado de Cantabria; art. 11.2 Decreto Legislativo 1/2015, de 12 noviembre, por el que se aprueba el Texto refundido de Ley de Prevención Ambiental de Castilla y León. 
nes que, unidas a las medidas correctoras, permiten conciliar la viabilidad económica y social del proyecto con las exigencias ambientales(116). En teoría, el proyecto sobre el que versa la evaluación ambiental no debería variar si el mismo se somete a autorización ambiental integrada, lo que no siempre sucede (117). Por ello, en este apartado se señalarán las previsiones que establece la legislación en esta materia y que puedan incidir en la determinación del daño ambiental si se produjera el cese de la acti$\operatorname{vidad}(118)$.

La Ley 21/2013, de 9 de diciembre, de Evaluación Ambiental (LEA) desdobla el procedimiento en dos fases, aunque es más correcto señalar que sólo existe una tramitación ante el órgano ambiental. La anterior se desarrolla ante el órgano sustantivo y permite llevar a cabo consultas y el proceso participativo antes de remitir el Estudio de Impacto Ambiental al órgano ambiental para su examen técnico (119). Ese documento debería contener las características del suelo o de las aguas antes del inicio de la actividad y, sin embargo, en la Ley se silencia ese aspecto(120). La Declaración de Impacto Ambiental (DIA) omite incluir el estado de los elementos del medio físico entre los aspectos a desarrollar(121) y sorprende todo ello porque las medidas correctoras deben basarse en la situación original de aquellos elementos. Sin esa información es difícil saber en qué medida y cómo pueden neutralizarse los impactos ambientales del proyecto(122). Tan sólo el promotor que solicite al órgano ambiental el documento de alcance debe realizar un diagnóstico territorial y del medio

(116) RAZQUIN LIZARRAGA, J.A., La evaluación de impacto ambiental, Aranzadi, Elcano, 2001, pp. 265-269.

(117) QUINTANA LÓPEZ, T., "La evaluación ambiental. Hitos de su evolución», en QUINTANA LÓPEZ, T. (Dir.) y CASARES MARCOS, A.B. (coord.), Evaluación de impacto ambiental y evaluación estratégica,Tirant lo Blanch, Valencia, 2014. pp. 33 y 34.

(118) NIETO MORENO, J.E., Elementos estructurales de la Evaluación ambiental de planes y programas, Revista Aranzadi de Derecho Ambiental, Monografía, 17, 2011, pp. 104-109.

(119) GARCÍA URETA, A., "Comentarios sobre la Ley 21/2013, de Evaluación Ambiental», RAP, 194, 2014, p. 331. Véase también, "Apuntes sobre la Ley de Evaluación Ambiental», leZ (Ingurumena eta Zuzenbidea), 12, 2014, pp. 113-123. Asimismo, RUIZ DE APODACA ESPINOSA, A., «Marco jurídico de la evaluación ambiental. La Ley 21/2013, de 9 de diciembre de Evaluación Ambiental», en RUIZ DE APODACA ESPINOSA, A. (Dir.), Régimen jurídico de la evaluación ambiental. Comentario a la Ley 2172013, de 9 de diciembre, de Evaluación Ambiental, Aranzadi, Cizur Menor, 2014, in toto.

(120) Art. 35.1 LEA.

(121) Art. 45.1 LEA.

(122) GARCÍA URETA, A., "La Directiva 2014/52 de Evaluación de Impacto Ambiental de Proyectos", en GARCÍA URETA, A. (coord.), La Directiva de la Unión Europea de evaluación de impacto ambiental de proyectos: balance de treinta años, Marcial Pons, Madrid, 2016, p. 206. Critica el hecho de que la Directiva no establezca una enumeración exhaustiva de la información a remitir a la autoridad competente. 
ambiente afectado por el proyecto(123). El contenido mínimo del estudio de impacto, previsto en el anexo VI LEA, se ha considerado básico por el TC, sin perjuicio de que las Comunidades autónomas puedan establecer en su normativa contenidos adicionales (124).

Sin embargo, para la evaluación de planes y programas la Ley obliga al promotor a incluir en su declaración ambiental estratégica «Los aspectos relevantes de la situación actual del medio ambiente y su probable evolución en caso de no aplicación del plan o programa» (125). Además, no pueden olvidarse las características ambientales de las zonas afectadas y «su evolución teniendo en cuenta el cambio climático esperado en el plazo de vigencia del plan o programa»(126). De todos modos, estas informaciones no pueden compararse ni asimilarse a los informes base exigidos para determinadas actividades. Así, el legislador presupone que el uso, producción o emisión de sustancias peligrosas se someterá a autorización ambiental integrada y, por ello, entiende apropiado no duplicar los trámites y presentar esa documentación en el procedimiento posterior. Aún así, no deja de sorprender que la adopción de las medidas correctoras se fundamente en descripciones o documentos de alcance cuyo contenido tampoco se halla suficientemente definido(127). Además, la solicitud del documento de alcance se ha convertido en un trámite voluntario para el promotor según la Ley estatal(128). Las comunidades autónomas, en cambio, pueden exigir la solicitud de este documento, al no considerarse un aspecto básico de la legislación ambiental (129).

(123) Art. 34.2 c) LEA. No se definen los aspectos que engloba el término diagnóstico y todo ello le otorga un margen muy amplio al órgano ambiental para elaborar el documento de alcance.

(124) STC 53/2017, de 11 de mayo, FJ 9. ${ }^{\circ}$

(125) Véase también, respecto a la evaluación estratégica, el art. 24.2 Ley 14/2014, de 26 diciembre, de Armonización y simplificación en materia de protección del territorio de Canarias. Para la evaluación de proyectos, puede consultarse el art. 32.1 en parecidos términos en cuanto al estudio de impacto ambiental. En los mismos términos se expresa el anexo 3 b) y c) Ley 6/2009, de 28 abril, de Evaluación Ambiental de Cataluña. ROSA MORENO, J., "Planes, programas y proyectos sometidos a evaluación (de impacto y estratégica ambiental)", QUINTANA LÓPEZ, T. (Dir.), Evaluación de impacto...., cit., 2014, p. 123.

(126) Anexo IV LEA.

(127) SANTAMARÍA ARINAS, R.J., "Evaluando al evaluador: razones técnicas, jurídicas y políticas en la evaluación de impacto ambiental de proyectos», en GARCÍA URETA, A. (coord.), La Directiva de la Unión Europea..., cit., 2016, p. 49. Pone de manifiesto los términos y criterios tan vagos e indeterminados que recoge la legislación para elaborar el estudio de impacto ambiental, además de aquellos umbrales que pueden considerarse tolerables.

(128) CARBALLEIRA RIVERA, T., «EI procedimiento de evaluación de impacto ambiental de proyectos», en QUINTANA LÓPEZ, T. (Dir.), Evaluación de impacto..., cit., 2014, p. 275.

(129) Véase STC 53/2017, de 11 de mayo, FJ $8 .^{\circ}$ No se considera básica el art. 34.1, apartado segundo, en lo relativo a considerar voluntario el documento de alcance, de modo que las comunidades autónomas pueden obligar al promotor a solicitarlo al órgano ambiental antes de iniciar el procedimiento de evaluación de impacto ambiental de proyectos. 
Resulta curiosa la omisión legislativa porque la Directiva en materia de evaluación de impacto ambiental de proyectos obliga al promotor a facilitar una información más detallada que la que señala la LEA. En concreto, debe realizar "una descripción de los aspectos pertinentes de la situación actual del medio ambiente (hipótesis de referencia) y una presentación de su evolución probable en caso de no realización del proyecto en la medida en que los cambios naturales con respecto a la hipótesis de referencia pueden evaluarse mediante un esfuerzo razonable teniendo en cuenta la disponibilidad de información medioambiental y de conocimientos científicos»(130). Esta previsión alberga más sentido y en ese aspecto probablemente la Ley precise alguna modificación.

Con arreglo a la legislación autonómica catalana, deben incluirse en el estudio de impacto las características del suelo en el que se emplaza la actividad proyectada, siempre y cuando esta actividad esté definida como potencialmente contaminante del suelo por la normativa específica de aplicación(131). En Navarra, por ejemplo, no se alude a ningún tipo de información relacionada exclusivamente con los elementos del medio físico, sino con el modo en que pueden resultar afectados por la instalación(132). Más explícita y completa es la Ley manchega, al requerir que el estudio de impacto ambiental contenga " Inventario ambiental, con una descripción de los elementos del medio ambiente que puedan verse afectados de forma apreciable por el proyecto, y en particular la población, la fauna y flora y sus respectivos hábitats, la geomorfología, el suelo, el agua, el aire, el clima, el paisaje, la estructura y función de los ecosistemas naturales, las áreas protegidas y los bienes materiales, incluido el patrimonio histórico, así como, en su caso, sus respectivas interacciones» (133). El aspecto positivo de esta previsión es que no se limita a las características que presenta el suelo, sino que extiende el contenido hasta los hábitats, ecosistemas o la flora.

(130) Anexo IV Directiva 2011/92/UE del Parlamento Europeo y del Consejo, de 13 de diciembre de 2011, relativa a la evaluación de las repercusiones de determinados proyectos públicos y privados sobre el medio ambiente.

(131) Art. 17.1 Ley 20/2009, de 4 de diciembre, de Prevención y Control Ambiental de Cataluña.

(132) Art. 39.1 a) Ley Foral 4/2005, de 22 marzo, de Intervención para la Protección Ambiental de Navarra. Se entiende, al igual que para el Decreto Legislativo 1/2015, de Castilla y León, que debe aplicarse la normativa estatal para la configuración del contenido del estudio de impacto (art. 56.1). Del mismo modo, la legislación de Aragón mimetiza el contenido de la LEA y no introduce ese examen previo de los elementos del medio físico, ni en el estudio de impacto ni en la declaración. Véase art. 15.2 Ley 11/2014, de 4 de diciembre, de Prevención y Protección Ambiental de Aragón.

(133) Art. 8.1 c) Ley 4/2007, de 8 marzo, de Evaluación Ambiental de Castilla-La Mancha. La idea de una suerte de inventario ambiental también la recoge el art. 27.1 c) Ley 11/2006, de 14 de septiembre, de evaluaciones de impacto ambiental y evaluaciones ambientales estratégicas en las Islas Baleares. La Ley 3/1998, de 27 de febrero, de Protección del Medio Ambiente del País Vasco obliga a incluir en el estudio un «inventario ambiental y descripción de las interacciones ecológicas o ambientales claves» [art. 45.c)]. 


\section{Legislación sobre residuos y suelos contaminados}

La Ley 22/2011, de 28 de julio, de Residuos y Suelos contaminados (LRSC), no permite despejar la incógnita en torno a qué suelos o actividades deben presentar informes acerca de la calidad y estado del suelo. Así, aquella norma prevé que el Gobierno aprobará y publicará una lista de actividades potencialmente contaminantes de suelos. Los titulares de aquéllas han de remitir periódicamente a la Comunidad autónoma correspondiente los informes en los que figure la información que pueda servir de base para la declaración de suelos contaminados(134). La Ley no emplea la expresión «sustancias peligrosas", sino que se refiere a las actividades que pueden causar contaminación, incluso a lo largo de un periodo determinado de tiempo(135). Además, el régimen de responsabilidad es más riguroso que el previsto en la LRM, ya que los operadores o responsables deben asumir los costes, sin que siquiera quepa la inversión de la carga probatoria(136).

A renglón seguido, la Ley ordena a las comunidades autónomas la elaboración de informes de delimitación y declaración de suelos contaminados cuando existan componentes peligrosos procedentes de las actividades humanas. En esos informes han de evaluar los riesgos para la salud humana o el medio ambiente, de acuerdo con criterios y estándares que determinará el Gobierno previa consulta a las comunidades autónomas (137). Por tanto, cabe distinguir dos momentos: uno, cuando la actividad es potencialmente contaminante, en la que se exigirán informes periódicos a los promotores(138); y, el otro, en caso de que el suelo sea declarado contaminado, por la presencia de componentes peligrosos para la salud humana o el medio ambiente. Esta última fase pertenece a la reparación o el restablecimiento del bien, mientras que la primera puede considerarse preventiva(139).

En caso de que cese definitivamente la actividad, el órgano ambiental podrá evaluar la calidad del suelo y decidir la reparación o el restablecimiento del mismo, sin perjuicio de que se hayan ocasionado daños a

(134) Art. 33.1 y 2 LRSC. Al respecto, véase BOLAÑO PIÑEIRO, M.C., «Responsabilidad en la limpieza...n, cit., 2015, p. 342. Incluso, el listado de sustancias potencialmente contaminantes no es cerrado.

(135) SANZ RUBIALES, I. y DE LA VARGA PASTOR, A., "Regulación, problemática...», en GARCíAMORENO RODRÍGUEZ, F. (Dir.), Comentarios sistemáticos..., cit., 2014, p. 460.

(136) VALENCIA MARTÍN, G., "Responsabilidad...», cit., 2010. El autor duda en torno a si puede o no aplicarse la exención de sufragar costes a los operadores o propietarios.

(137) Art. 34.1 LRSC.

(138) SANZ RUBIALES, I. y DE LA VARGA PASTOR, A.,, "Regulación, problemática...», cit., 2014, p. 464. Estos informes consisten, según su criterio, en "La puesta en conocimiento de la Administración de unos datos juzgados relevantes y que entraña un deber de colaboración con ella».

(139) DE MIGUEL PERALES, C., Régimen jurídico español de los suelos contaminados, ThomsonCivitas, Madrid, 2007, pp. 78-89. 
otros elementos del medio físico, como cauces subterráneos, flora y fauna. La responsabilidad por estos últimos se somete a la legislación sobre responsabilidad ambiental, sin perjuicio de que se adopten soluciones conjuntas, al objeto de integrar todos los elementos en un mismo emplazamiento como si fuera desde el origen(140). De este modo, las actividades que se ejerzan con posterioridad disponen de información en torno al estado del suelo desde que comenzaron, lo que facilitará enormemente su reparación o, en su caso, el restablecimiento del resto de elementos del medio físico(141). Ahora bien, de nuevo se suscita el interrogante en torno al modo en que esa reparación desde el origen se llevará a cabo si los promotores que funcionaban con anterioridad a esa fecha no elaboraron una especie de estudio base o un informe de referencia que permita apreciar las diferencias y la alteración de los elementos del medio físico desde el inicio hasta el fin de la actividad.

El informe base, solicitado para la autorización ambiental integrada, si la actividad emplea, produce o emite sustancias peligrosas, coincide aquí en este último aspecto con la declaración de calidad del suelo. De ese modo, las actividades que precisan un informe base también deberán someterse a un informe de calidad del suelo en caso de que se detecte el carácter peligroso de las sustancias o componentes que alberga ese suelo. Otro asunto es que puedan coincidir en cuanto a su alcance, pero lo cierto es que deberían presentar elementos en común y puede plantearse, incluso, la posibilidad de unificar el trámite.

Con un carácter preventivo, se obliga a los operadores a presentar un informe periódico cuyo contenido no se precisa y tan sólo se señala la posibilidad de que sirva de base para la declaración de suelos contaminados(142). Recuérdese que el anexo I del RD 9/2005 detalla todas aquellas actividades potencialmente contaminantes del suelo. Es loable el intento del legislador por alcanzar una definición más acertada del daño ambiental

(140) DE LA VARGA PASTOR, A., El nuevo régimen jurídico de los suelos contaminados, La Ley, 2012, pp. 123-127.

(141) ALONSO IBÁÑEZ, M.R., Suelos contaminados, prevención y recuperación ambiental, Civitas, Madrid, 2012, pp. 78-85.

(142) Esta obligación de remitir informes periódicos ya se había implantado en el art. 3.1 del RD 9/2005, de 14 de enero, por el que se establece la relación de actividades potencialmente contaminantes del suelo y los criterios y estándares para la declaración de suelos contaminados, y este precepto debe entenderse aplicable hoy en día: "Los titulares de las actividades relacionadas en el anexo I estarán obligados a remitir al órgano competente de la Comunidad Autónoma correspondiente, en un plazo no superior a dos años, un informe preliminar de situación para cada uno de los suelos en los que se desarrolla dicha actividad, con el alcance y contenido mínimo que se recoge en el anexo Il». No obstante, debe notarse que estos informes preliminares de situación deben presentarlos las empresas que se recogen en el anexo I y algunas otras que se indican en el art. 3.2 del RD. Se caracterizan por producir un significativo impacto ambiental, como las que manejan sustancias peligrosas en más de 10 toneladas al año. 
en cada caso(143) y, en consecuencia, la obligación de reparar, pero quedan cuestiones pendientes, como la necesidad de que ese informe sea más preciso e incluya diversos elementos del medio físico. Permitiría mejorar el diagnóstico sobre el impacto de la actividad que ha ido generándose con el paso de tiempo y adoptar medidas ante los riesgos que comporta(144). La transferencia de la contaminación entre elementos del medio físico requiere que la regulación de la responsabilidad sea unitaria, pues fragmentar la regulación impide una reparación del daño más integral.

En el ámbito autonómico se han aprobado algunas leyes específicas en esta materia de suelos contaminados, y algunas introducen ciertas particularidades y mayor desarrollo, lo que contribuye a mejorar sensiblemente las cuestiones ligadas a la responsabilidad. La legislación canaria remite al RD 9/2005 para determinar las actividades cuyos titulares deben presentar informes preliminares de situación (145). Sin embargo, el anexo del Decreto canario contempla el alcance y contenido mínimo exigido para ese informe. A continuación, a los promotores que lleven a cabo esas actividades potencialmente contaminantes se les pueden exigir informes de situación del suelo cuando se establezca, amplíe o clausure la actividad, si bien su contenido debe fijarlo el Gobierno por la vía reglamentaria. En Extremadura los propietarios del suelo deben presentar un informe de situación cuando se solicite una autorización para el desarrollo de una actividad no contaminante(146).

Por lo que respecta al contenido de los informes de situación, en la Comunidad de Madrid se ha previsto que se elabore un estudio hidrogeológico y un «muestreo y análisis del suelo y de las aguas subterráneas» (147). Todos estos informes precisan una aprobación previa del órgano ambiental, al objeto de que éste adopte las medidas correspondientes, como mo-

(143) BLÁZQUEZ ALONSO, N. y PICÓ BARANDIARAN, E., "La regulación de los suelos contaminados en la Ley 22/2011, de 28 de julio, de Residuos y Suelos Contaminados", Revista de Derecho Urbanístico y Medio Ambiente, 279, 2013, pp. 119-123.

(144) SANZ RUBIALES, I. y DE LA VARGA PASTOR, A., "Regulación, problemática...», cit., 2014, pp. 503 y 504. En ese sentido, la misma descontaminación o el control sobre el suelo representa un elemento de prevención.

(145) Art. 4 Decreto 147/2007, de 24 de mayo, por el que se regula el régimen jurídico de los suelos contaminados en la Comunidad Autónoma de Canarias y se crea el Inventario de Suelos Contaminados de Canarias. Se faculta a la Administración a requerir a los promotores nuevos informes complementarios, así como datos, análisis o aclaraciones que permitan evaluar la contaminación del suelo.

(146) Decreto 49/2015, de 30 de marzo, por el que se regula el régimen jurídico de los suelos contaminados en la Comunidad Autónoma de Extremadura. En parecidos términos en Extremadura la periodicidad de los informes es de 5 años. También prevé informes de situación simplificados que son voluntarios. Véase también art. 5.2 Decreto 60/2009, de 26 de febrero, de Suelos Potencialmente Contaminados y procedimiento para la declaración de suelos contaminados de Galicia.

(147) DT 2. ${ }^{a}$ Decreto 326/1999, de 18 de noviembre, por el que se aprueba el régimen jurídico de los suelos contaminados de la Comunidad de Madrid. 
dificar las condiciones de las autorizaciones o las medidas correctoras incluidas en la DIA(148). En la Comunidad Autónoma vasca se distinguen dos procedimientos: uno, la declaración en materia de calidad del suelo y, dos, el procedimiento de declaración de aptitud de uso del suelo. El procedimiento de calidad permite conocer las concentraciones de sustancias en el suelo y en otros elementos, lo que añade más garantías y, en función de ese examen, puede decidirse si el suelo es apto para su uso actual o previsto (149). La declaración de aptitud del suelo, en cambio, tiene por objeto validar la capacidad del suelo exclusivamente para uso industrial. En estos casos se requiere un informe de situación del suelo(150).

Los informes periódicos, a tenor de la legislación vasca, se entregan en un periodo de tiempo que depende de la intensidad de la contaminación y del tipo de actividad. El órgano ambiental les requerirá la entrega de más o menos información en función de esas distintas categorías de actividades(151). El interés por llevar a cabo un examen más exhaustivo de la situación del suelo se refleja en la Ley vasca, al introducir dos figuras como la investigación detallada y la investigación exploratoria de la calidad del suelo. La primera puede ordenarse para permitir una correcta delimitación del tipo, concentración y distribución de las sustancias contaminantes en el suelo y en el resto de medios en los casos en que el riesgo de contaminación no es aceptable. La investigación exploratoria se refiere a una investigación histórica que contribuye a delimitar las sustancias contaminantes que se han liberado en la realización de otras actividades(152). Las declaraciones de calidad del suelo deben emitirse en caso de que cese la actividad o cuando se implante o instale una nueva en un suelo que haya soportado una actividad o instalación potencialmente contaminante(153). Aún así, no se establece la obligatoriedad de un informe de situación para los suelos que en el futuro se usen por actividades potencialmente contaminantes. Al aplicarse la LPCIC, este informe base correspondería a las instalaciones que emitan, produzcan o usen sustancias peligrosas relevantes.

(148) Art. 7 Decreto 60/2009, de 26 de febrero, de Suelos Potencialmente Contaminados y procedimiento para la declaración de suelos contaminados de Galicia. Estas medidas también pueden ser modificadas de oficio con audiencia de las personas interesadas.

(149) BOLAÑO PIÑEIRO, M.C., "Responsabilidad en la limpieza...», cit., 2015, p. 362.

(150) Art. 7.2 y 3 Ley 4/2015, de 25 de junio, de Prevención de la Contaminación del suelo del País Vasco.

(151) Art. 8.2 Ley 4/2015, vasca de Suelos Contaminados.

(152) Arts. 9 y 10 Ley 4/2015, vasca de Suelos Contaminados.

(153) Art. 23.1 a) y c) Ley 4/2015, vasca de Suelos Contaminados. En cualquier caso, ha de examinarse si las medidas de reparación que incluyan la declaración de calidad del suelo van anudadas a una obra previa cuya construcción se somete a la aprobación definitiva y previa del Plan Parcial correspondiente. Véase STSJ País Vasco 29 de mayo de 2014, RJCA 2014/604, FD $8 .^{\circ}$ y $9 .^{\circ}$ La declaración de calidad del suelo deviene inválida e ineficaz porque contempla medidas que se refieren a proyectos que, en principio, no se ajustan al Plan Parcial correspondiente. 
Por último, en Andalucía los informes históricos de situación también deben ser presentados por los propietarios, en caso de que haya un cambio de uso del suelo y éste haya sido utilizado para realizar actividades potencialmente contaminantes(154). Al hilo de lo que se ha comentado anteriormente para la legislación vasca, en Andalucía no se impone la obligación de llevar a cabo un informe de situación u otro tipo de informe, salvo que sea una actividad que emplee sustancias peligrosas antes del inicio de la actividad. Tan sólo se les obliga a los operadores a dejar constancia de la actividad en el registro correspondiente y a presentar informes periódicos.

\section{Conclusiones}

Primera. Al margen del escaso tiempo que lleva aplicándose en España la Ley $26 / 2007$, es una regulación que requiere adaptarse a la crisis del sector secundario, al menos en nuestro entorno, $y$ al hecho de que el desmantelamiento del tejido industrial se perfila como la tendencia en los próximos años. El título de este trabajo menciona la expresión "regulación integradora" para referirse a la necesidad de que la responsabilidad ambiental se rija por unas normas que no dependan exclusivamente del régimen relativo a las actividades clasificadas, o de la prevención y control integrados de la contaminación o de los suelos contaminados o de la biodiversidad. Si realmente la Unión Europea y los estados pretenden materializar el firme propósito de implantar un único régimen de responsabilidad ambiental, han de afrontar determinadas cuestiones que se exponen a continuación.

Segunda. Si se admite la existencia de daños acumulativos o históricos, como parece que implícitamente se desprende de la legislación, debe aclararse de una vez el régimen de recuperación de costes para los operadores que observen las condiciones establecidas en la autorización. No todos los suelos o los elementos presentan igual grado de resiliencia en función de diferentes factores $y$, en consecuencia, unos han podido quedar más afectados que otros. Así, más allá de que se hayan cumplido los umbrales, estándares o valores límite de emisión, el operador que cesa en la actividad debe llevar a cabo el correspondiente examen o estudio del elemento del medio físico, si así se lo exige la Administración, o bien elaborar el informe base, de situación o de calidad de suelo, si así le corresponde de acuerdo con la Ley.

Tercera. En la misma Ley de responsabilidad medioambiental o en el reglamento deben precisarse todos aquellos aspectos o materias que debe contener un informe de situación o base. Además, para conocer mejor el

(154) Art. 55.1 Decreto 18/2015, de 27 de enero, de la Junta de Andalucía, por el que se aprueba el reglamento que regula el régimen aplicable a los suelos contaminados. 
estado básico de los elementos ambientales, la propia legislación en materia de responsabilidad ha de concretar la información exacta que deben presentar los operadores al órgano ambiental, tanto si solicitan una autorización ambiental integrada como si la actividad está sometida a EIA. La determinación del daño, su alcance, las medidas de reparación, el nexo causal, la corrección y la prevención o precaución para el futuro, depende de la información acerca de la situación originaria del elemento ambiental. Un conocimiento vago o no muy exhaustivo puede provocar la transferencia de la contaminación y una deficiente restauración del bien.

Cuarta. Debe preverse expresamente, también a través de la Ley de Responsabilidad Ambiental, que, si los bienes ambientales han sido dañados, la responsabilidad ambiental se dirima exclusivamente a través del procedimiento administrativo que establece la LRM y con las garantías que ésta prevé. Así, si cesa la actividad y el operador ha sido acusado en la vía penal o en la administrativa, se evita una suerte de procedimientos paralelos en la vía administrativa, o la inaplicación de la LRM si se ha incoado un proceso penal o se ha recurrido la sanción en la vía contencioso-administrativa. Si esta opción resulta inviable, al menos el legislador debería precisar qué aspectos deben ser sometidos exclusivamente a la responsabilidad ambiental, como la cuantificación de los daños o qué medidas deben adoptarse.

Quinta. El cese de la actividad viene precedido, en ocasiones, de procesos de quiebra o de dificultades económicas por parte del operador. Asumir el coste de las medidas por parte de la Administración en la actualidad parece una solución de último recurso, toda vez que se les ha obligado a aquellos a suscribir seguros o contratar garantías financieras. Sin embargo, no siempre las coberturas resultan suficientes para sufragar reparaciones $y$, en esos casos, exigir a la Administración que afronte el coste restante sería desproporcionado si el operador ha obtenido beneficios que luego han ido menguando o desapareciendo.

Sexta. Si se acepta el concepto de daño acumulativo a elementos del medio físico, no solamente por el uso, producción o emisión de sustancias peligrosas, y teniendo en cuenta el principio de precaución, debería exigirse un informe al operador que cesa en la actividad, aunque sólo haya empleado o producido sustancias potencialmente contaminantes. Esta distinción entre sustancias peligrosas y contaminantes o potencialmente contaminantes ignora el carácter continuado, histórico y acumulativo del daño en los elementos del medio físico.

Trabajo recibido el 27 de julio de 2017

Aceptado por el Consejo de Redacción el 20 de octubre de 2017 
LABURPENA: Gaur egun jarduera industrialak behera egin du nabarmenki, eta horrek esan nahi du gero eta enpresa gehiagok jarduera utzi behar dutela. Ingurune fisikoari lotutako elementuak kutsatzen duten instalazioak eraikitzen badituzte, ingurumen-erantzukizuna xedatzen duten arauei men egin behar diete, kaltea eta kaltetutako ondasunak berrezartzeko neurriak har ditzaten. Lan honek zalantzak argitzea du xede zenbait gaitan, esaterako, kaltea zehaztu, kalte historikoen edo jarraituen eta operadorearen erantzukizunaren gainean. Halaber, baimenak eta Administrazioak duen esku hartzeko baliabideak aztertzen dira, ezagutzeko ea ezartzen dituzten tresnak ingurumen-erantzukizunari dagozkion arauak osatu, hobetu edo garatzen dituztenak. Azkenik, ingurumen-erantzukizunari araubide batua ematen dioten proposamenak azaltzen dira, behintzat teknikoki funtsezkoak diren kontuetan, adibidez, hartu beharreko neurriak eta diru kopurua zehaztea.

GAKO HITZAK: Erantzukizuna. Ingurumena. Operadoreak. Industria. Uztea.

RESUMEN: En la actualidad ha decrecido sensiblemente la actividad industrial y eso significa que cada vez más empresas deben cesar en su actividad. Si han llevado a cabo actividades que pueden contaminar elementos del medio físico, deberían someterse a las normas sobre responsabilidad medioambiental para determinar el daño y las medidas que han de adoptar para restaurar los bienes dañados. Este trabajo tiene por objeto solventar algunas dudas que presenta la normativa en materia de responsabilidad ambiental en ciertos aspectos, como la determinación del daño, los daños históricos o acumulativos y la responsabilidad del operador. Asimismo, se analizan los permisos y técnicas de intervención administrativa para conocer si establecen mecanismos que complementen, mejoren o desarrollen los remedios que ofrece la normativa sobre responsabilidad ambiental. Por último, se presentan unas propuestas que tienen por objeto dotar de un régimen unificado a la responsabilidad ambiental, al menos en aspectos técnicamente esenciales como las medidas a adoptar y su cuantificación.

PALABRAS CLAVE: Responsabilidad. Medio ambiente. Operadores. Industria. Cese.

ABSTRACT: Currently industrial activity has decreased significantly and that means more and more individual companies need to close it down. In case they settle industrial facilities that can pollute elements of the environment, they should be subject to the rules on environmental liability in order to determine the liability and the measures they must take to restore the damaged goods. This work is aimed at solving some doubts raising the legislation about the environmental liability regarding some aspects, such as the definition of the damage, historical or sustained damages and operator's accountability. Likewise, licences and permits are analyzed in order to know whether they set mechanisms complementing, improving or developing the regulation on environmental liability. Finally, some suggested improvements are proposed that are aimed at achieving a unified regime for the environmental liability, at least on technically essential issues, like the necessary measures and their economic value.

KEYWORDS: Liability. Environment. Operators. Industry. Cessation. 